\title{
Designing and Optimizing Heat Storage of a Solar-Assisted Ground Source Heat Pump System in China
}

\author{
Yan Gao, ${ }^{1,2}$ Zhi Sun, ${ }^{2}$ Xinxing Lin, ${ }^{3}$ Chuang Wang $\mathbb{D}^{1,2}{ }^{1,2 o n g y u}$ Sun, ${ }^{4}$ and Yanhong Chen ${ }^{5}$ \\ ${ }^{1}$ Beijing Advanced Innovation Center for Future Urban Design, Beijing University of Civil Engineering and Architecture, \\ Beijing 100044, China \\ ${ }^{2}$ Beijing Key Lab of Heating, Gas Supply, Ventilating and Air Conditioning Engineering, Beijing University of Civil Engineering \\ and Architecture, Beijing 100044, China \\ ${ }^{3}$ Key Laboratory of Efficient Utilization of Low and Medium Grade Energy, MOE, Tianjin University, Tianjin 300072, China \\ ${ }^{4}$ China Academy of Building Research, Beijing 100013, China \\ ${ }^{5}$ Mechanical and Electrical Engineering Institute of Kaifeng University, Kai Feng 475004, China
}

Correspondence should be addressed to Chuang Wang; wangchuang@bucea.edu.cn

Received 11 October 2019; Revised 17 November 2019; Accepted 2 December 2019; Published 24 February 2020

Guest Editor: Chuanchang Li

Copyright ( 2020 Yan Gao et al. This is an open access article distributed under the Creative Commons Attribution License, which permits unrestricted use, distribution, and reproduction in any medium, provided the original work is properly cited.

\begin{abstract}
The cold accumulation problem can lead to performance degradation of heat pumps. This paper presents the design and optimization of a solar-assisted storage system to solve this issue. A ground source heat pump (GSHP) project was established using the transient system simulation program (TRNSYS) based on a ground heat exchange theoretical model, which was validated by a previously established experiment in Beijing. The Beijing, Harbin, and Zhengzhou regions were used in numerical simulations to represent three typical cities where buildings require space heating (a cold region, a severe cold region, and a hot summer and cold winter region, respectively). System performance was simulated over periods of ten years. The simulation results showed that the imbalance efficiencies in the Beijing, Harbin, and Zhengzhou regions are 55\%, 79\%, and 38\%, respectively. The annual average soil temperature decreases $7.3^{\circ} \mathrm{C}, 11.0^{\circ} \mathrm{C}$, and $5.3^{\circ} \mathrm{C}$ during ten years of conventional GSHP operation in the Beijing, Harbin, and Zhengzhou regions, respectively. Because of the soil temperature decrease, the minimum heating coefficient of performance (COP) values decrease by $23 \%, 46 \%$, and $11 \%$ over the ten years for GSHP operation in these three regions, respectively. Moreover, the simulation data show that the soil temperature would still be decreasing if based on the previous solar energy area calculation method. Design parameters such as the solar collector size are optimized for the building load and average soil temperature in various cold regions. Long-term operation will test the matching rate of the compensation system with the conventional GSHP system. After the system is optimized, the solar collector area increases of $20 \%$ in the Beijing region, $25 \%$ in the Harbin region, and $15 \%$ in the Zhengzhou region could help to maintain the annual average soil temperature balance. The optimized system could maintain a higher annual average COP because of the steady soil temperature. It provides a method for the design of a solar collector area which needs to be determined in the seasonal heat storage solar ground source heat pump system.
\end{abstract}

\section{Introduction}

Compared with outdoor air, the ground retains a relatively stable temperature because of its large heat mass. The ground can be used as a heat source or sink to meet the needs of ground source heat pump (GSHP) systems for heating and cooling of building spaces. In recent years, many GSHP systems have been developed and installed because of their environmentally friendly performance and high efficiency [1]. Ground heat exchangers (GHEs) are an emerging technology, which are an important component of GSHP systems for extracting ground heat during the heating season and 
injecting absorbed dwelling heat into the ground during the cooling season [2]. In established GSHP systems, highperformance GHEs result in lower $\mathrm{CO}_{2}$ emissions and less electrical load on the power grid.

However, under the two main working conditions dominated by heating and cooling, there can be a large gap between the heating and cooling load which the ground self-recovery cannot match [3]. In China, the government has encouraged GSHP systems for conventional heating, ventilation, and air conditioning. Thus, China has become the largest GSHP-system-practicing nation in the world. After several years of continuously increasing sales, the GSHP market share reached $7 \%$ of the total central air conditioning market by 2010. However, the market share of GSHP systems has shown a downtrend in recent years and decreased to $2.2 \%$ by 2016 [4]. Some GSHP systems installed several years ago have now been decommissioned for not achieving the desired energy savings, especially in typically cold regional cities such as Shenyang in northeast China [5]. When GSHP systems are used in cold regions, more heat is extracted from the ground than is injected back into it. This leads to cold accumulation and long-term decreases in soil temperature. This thermal imbalance over a long-term operation decreases the temperature recovery ability, degrades the heating performance of GSHP systems, and can lead to complete GSHP system failure [6]. Studies indicate that heat injected into the ground and heat extracted from the ground should balance, to preserve the geothermal resource for sustainable utilization as a heat source or sink [7]. To achieve this, studies suggest that partial compensation between winter heating and summer cooling is necessary for a single line or two staggered lines of infinite GHEs, even with a large distance between adjacent GHEs. For a square field of infinite GHEs, near complete compensation of winter and summer loads is necessary [8].

Compensation heat sources such as gas boilers, waste heat sources, and solar collectors can be used to avert this annual energy imbalance and solve this problem in cold regions. To extract less heat from the ground, gas boilers are commonly used during the peak heating load, and the GSHP system provides the remaining heating. Alavy et al. [9] investigated the characteristics of a GSHP system assisted by a gas boiler. A heating load ratio of $60 \%$ for the GSHP system and $40 \%$ for the gas boiler was found to be the most economical operation and did not lead to any obvious increase in energy consumption.

Another approach of compensating the heat into the ground from another energy source has also been explored. There are two approaches to heat storage: low-temperature storage and high-temperature storage. In the low-temperature heat storage, the heat is mainly used to compensate for the annual heat imbalance or to increase the ground temperature within several degrees $\mathrm{K}$ to increase the heat pump COP [10]. High-temperature heat storage is another approach to seasonal heat storage and requires higher input fluid temperature and insulation of a storage medium boundary [11]. Although the ground is rarely used as a high-temperature storage medium, water has proven to be a more effective seasonal heat storage medium. However, if there is no natural reservoir, such a system is more expensive than the ground storage system because of the need for a large tank (usually underground) to store water [12].

Solar energy is the most advantageous renewable energy source. It collects and converts the abundant energy of the sun into available energy. Evacuated tube collectors (and similar devices) convert solar energy into heat energy, which can be applied to the space of residential and commercial buildings or water heating and air conditioning. Hybrid GSHP systems compensate for the ground heat loss by providing additional heat into the soil. Energy storage technology, such as solar energy storage, is commonly applied to store natural underground energy [13]. Solar-assisted GSHPs (SA-GSHPs) installed for a residential building in Tianjin, China (a cold region similar to Beijing), were studied by Wang et al. The system performance during long operating periods was simulated by unit modeling, and its parametric effects were discussed [14]. The experimental results of Bakirci et al. showed that the coefficients of performance (COP) of the heat pump and the overall system were 3.03.4 and 2.7-3.0, respectively [15]. The results showed that SA-GSHPs could be used for residential heating in the cold region of Erzurum, Turkey. The study demonstrated that the hybrid GSHP system incorporating solar thermal collectors was feasible for the space conditioning for heatingdominated houses. Rad et al. reported that solar thermal energy storage in the ground could significantly reduce the necessary GHE length [16].

Lazzarin showed that compared with the independent GSHP system, the SA-GSHP system has a shorter length of heat exchanger and a lower investment cost [17]. Macía et al. showed the COP of the heat pump and the efficiency. The design method of the SA-GSHP system is evaluated to generate an analysis model and numerical model [18]. A house with GSHP and a solar seasonal heat storage system was simulated in Harbin, China. This study showed that the vertical ground heat exchanger model has better simulation results than the field data. Therefore, in the heating season, the average soil temperature and inlet and outlet temperature of the vertical surface heat exchanger decreased significantly. In general, the proposed system meets the heating and cooling requirements of buildings [19].

The performance of an SA-GSHP for heating a detached house in Harbin, China, was experimentally studied by Wang et al. The average COPs of the heat pump and overall system were 4.29 and 6.55 for operation in heating mode, respectively [20]. Karagiorgas et al. reported a hybrid system composed of a GSHP system and a solar-assisted GSHP system, along with a simulation model developed in TRNSYS (a transient system simulation tool) for predicting key issues in the design process [21].

Liu et al. carried out experimental research on a GSHP system with thermal energy storage under different loads. The results show that the heating and cooling capacity can be increased by $37.5 \%$ and $15.8 \%$, respectively, by integrating heat storage with the GSHP system [22]. The above studies asserted that SA-GSHPs are a promising technology for matching the gap between cooling and heating loads in cold regions, but solutions for $\mathrm{GHE}$ heat injection performance 


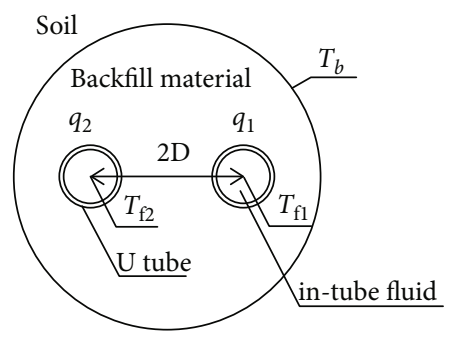

(a) Graphical representation

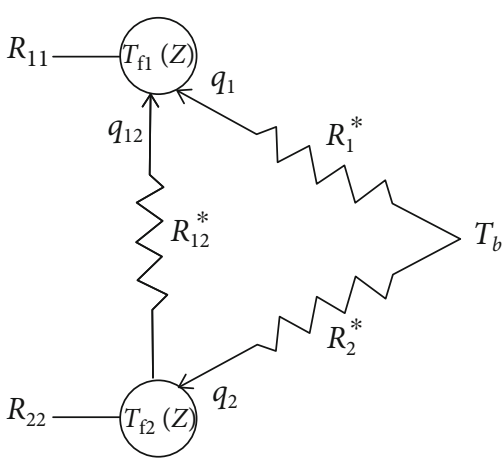

(b) Thermal resistance

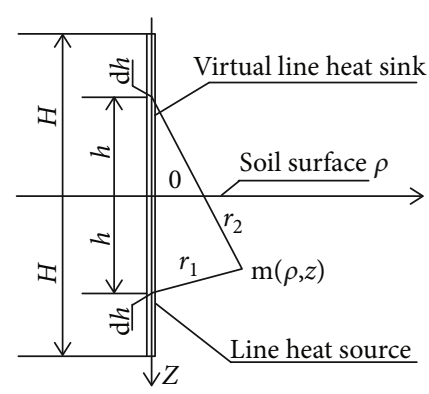

(c) $2 \mathrm{D}$ finite-line heat source model

FIGURE 1: Heat transfer network of the borehole.

are complex. The thermophysical properties of the ground and the operation of a compensation system are always the determinants of the size of the solar collector and water storage tank system [23].

The thermal transport efficiency of the GHE in the ground plays a vital role in the efficiency of the overall GSHP system, so the operation of GHEs should be examined carefully [24]. To reduce interference on the refrigerating process in summer, the heat storage process is usually applied in autumn. Considering the heat self-recovery in the soil, the sizes of the solar loops are usually optimized based on the results of long-term case studies. Simulation results are analyzed to determine the necessary parameter of the GSHP for storing heat in selected regions. Methods for determining the specific heat storage and heat storage mode are then developed.

A comprehensive review of the relevant literature of SAGSHP systems shows that a large amount of work has been done in terms of technical feasibility, detailed modeling, and field test experiments with many innovative ideas. It has been shown that the viability of an SA-GSHP system in residential sectors and the demand for heating and cooling are very high. One of the important aspects to be considered in the construction of SA-GSHP is to specify the optimal size of the system. Emmi et al. [25] demonstrated the factors for optimal size of solar hybrid systems and the importance of optimal size in the residential sector.

In this paper, the aim is to confirm whether the system needs specific heat storage and a heat storage mode. Based on the finite-line source model, the performance of GHEs is simulated. The ground thermal performance is studied by injection experiments, and the mathematics model is validated to optimize the energy storage. A simulation of the GSHP system combining solar seasonal energy storage is carried out to predict the long-term ground temperature field variation. The suitability of the systems to three regions in China was simulated. The surface temperature and system efficiency of the regenerative system are compared.

\section{Mathematical Modeling of GHEs}

Using solar energy for seasonal heat storage can overcome the ground thermal imbalance that occurs over long-term operation. For the long-term simulation of systems that include seasonal solar energy storage in this study, the GHE model needed to connect with other equipment, making the simulation complicated and time-consuming. Analytical methods have advantages in their lower computational expense and higher speed. A typical simulation model involves a composite linear source model to simulate the thermal processes of the borehole and pile. A reasonable prediction can then be made of the thermal behavior of the GHEs [25].

To build a two-dimensional (2D) finite-line source model in cylindrical coordinates, it is practical to determine the equivalent U-tube geometry, as illustrated in Figure 1. Figure 1(a) shows the physical configuration and relative positions of the working fluid, U-tube geometries, concentric grout, and soil. Figure 1(a) also shows the parameters characterizing the heat exchange process, such as the temperature of the borehole wall $\left(T_{\mathrm{b}}\right)$, the inlet fluid temperature $\left(T_{\mathrm{f} 1}\right)$, and the outlet fluid temperature $\left(T_{\mathrm{f} 2}\right)$. In Figure $1(\mathrm{~b}), R_{1}{ }^{*}$ and $R_{2}{ }^{*}$ are the equivalent thermal resistances between the fluid of two legs of the U-tube and the borehole wall, respectively. $R_{12}{ }^{*}$ is the equivalent thermal resistance from the fluid of one leg to another. $q_{1}$ and $q_{2}$ are the heat transfer rates per unit length from a certain leg to the borehole wall, respectively. $q_{12}$ is the heat rate per unit length pipe between two legs of the U-tube. As shown in Figure 1(c), the classical finite-line heat source model adopted in this study derives an analytical solution for the transient temperature response in a semi-infinite medium. The borehole is treated as a finiteline heat source.

If the thermal interference between the two adjacent legs of the U-tube is not considered, the proposed finiteline heat model can be used to analyze and calculate the heat conduction of the vertical boreholes for their longterm operation in GSHP systems. Therefore, the model is based on typical simplifying assumptions and is commonly utilized to address these types of problems. The specific assumptions are as follows:

(1) The thermal properties of the ground are constant and the soil is assumed to be isotropic

(2) Moisture migration is neglected 
(3) The borehole size is neglected, so the borehole can be regarded as a linear heat source

(4) The heat conduction along the borehole axis, including the heat flux through the surface and bottom of the borehole, is neglected to make the heat conduction one-dimensional

(5) There is considered to be no contact thermal resistance between the borehole and the ground

2.1. Heat Transfer Model inside the Borehole. The description of the borehole model consists of the resistances associated with the fluid, pipe, and grout. In accordance with Figure 1, the energy balance equation inside the borehole is given by the following equations:

$$
\left\{\begin{array}{l}
M_{\mathrm{c}} \frac{\partial T_{\mathrm{f} 1}(Z)}{\partial z}=\frac{\left[T_{b}-T_{\mathrm{f} 1}(Z)\right]}{R_{1}^{*}}+\frac{\left[T_{\mathrm{f} 2}(Z)-T_{\mathrm{f} 1}(Z)\right]}{R_{12}^{*}}, \\
-M_{\mathrm{c}} \frac{\partial T_{\mathrm{f} 1}(Z)}{\partial z}=\frac{\left[T_{b}-T_{\mathrm{f} 2}(Z)\right]}{R_{2}^{*}}-\frac{\left[T_{\mathrm{f} 2}(Z)-T_{\mathrm{f} 1}(Z)\right]}{R_{12}^{*}},
\end{array}\right.
$$

where $M_{c}$ is the total heat mass of the unit inside the borehole per length. The parameters $R_{1}{ }^{*}, R_{2}{ }^{*}$, and $R_{12}{ }^{*}$ are expressed as follows [26]:

$$
\left\{\begin{array}{l}
R_{1}^{*}=\frac{R_{11} R_{22}-\left(R_{12}\right)^{2}}{R_{22}-R_{12}}, \\
R_{2}^{*}=\frac{R_{11} R_{22}-\left(R_{12}\right)^{2}}{R_{11}-R_{12}}, \\
R_{12}^{*}=\frac{R_{11} R_{22}-\left(R_{12}\right)^{2}}{R_{12}},
\end{array}\right.
$$

where $R_{11}$ and $R_{22}$ are the thermal resistances between the circulating fluid in a certain U-tube leg and the borehole wall. $R_{11}=R_{22}$ when the U-tube legs are buried in the borehole symmetrically. $R_{12}$ is the resistance between the two individual legs. By analyzing the steady-state conduction problem in the borehole cross-section through the line source, the following relationships can be obtained [27]:

$$
\left\{\begin{array}{l}
R_{11}=\frac{1}{2 \pi k_{b}}\left[\operatorname{In}\left(\frac{r_{b}}{r_{p}}\right)+\frac{k_{b}-k}{k_{b}+k} \cdot \operatorname{In}\left(\frac{r_{b}^{2}}{r_{b}^{2}-D^{2}}\right)\right]+\frac{1}{2 \pi k_{p}}\left[\operatorname{In}\left(\frac{r_{p}}{r_{\mathrm{pi}}}\right)+\frac{1}{2 \pi k_{p i} h}\right], \\
R_{12}=\frac{1}{2 \pi k_{b}}\left[\operatorname{In}\left(\frac{r_{b}}{2 D}\right)+\frac{k_{b}-k}{k_{b}+k} \cdot \operatorname{In}\left(\frac{r_{b}^{2}}{r_{b}^{2}+D^{2}}\right)\right], \\
h=\frac{0.023 \operatorname{Re}^{0.8} \operatorname{Pr}^{n} \lambda_{f}}{d_{\mathrm{pi}}}
\end{array}\right.
$$

where $r_{b}$ is the radius of the borehole; $r_{p}$ and $r_{\mathrm{pi}}$ are the outer and inner radii of the pipe, respectively; $k$ is the conductivity of the grout; $k_{b}$ is the conductivity of the pipe material; $D$ is the distance between the centers of the pipe and borehole; and $h$ is the convective heat transfer coefficient. Using the method of Diao [28], the inlet and outlet temperatures with time can be obtained as

$$
\left\{\begin{array}{c}
T_{\text {in }}(\tau)=T_{b}(\tau)+\frac{Q}{\varepsilon \dot{m} c}, \\
T_{\text {out }}(\tau)=T_{\text {in }}(\tau)-\frac{Q}{\dot{m} c},
\end{array}\right.
$$

where $Q$ is the total heat transfer rate of the borehole, $\dot{m}$ is the total mass flow rate of the fluid, and the borehole heat transfer efficiency $\varepsilon$ and parameter $\beta$ are expressed as

$$
\varepsilon=\frac{\left(H / M_{c} \beta\right)\left(\left(1 / R_{1}^{*}\right)+\left(1 / R_{2}^{*}\right)\right) \operatorname{sh}(\beta)}{\operatorname{ch}(\beta)+\left(H / 2 M_{c} \beta\right)\left(\left(1 / R_{1}^{*}\right)+\left(1 / R_{2}^{*}\right)\right) \operatorname{sh}(\beta)},
$$

$$
\beta=\sqrt{\frac{H^{2}}{4\left(M_{c}\right)^{2}}\left(\frac{1}{R_{1}^{*}}+\frac{1}{R_{2}^{*}}\right)^{2}+\frac{H^{2}}{\left(M_{c}\right)^{2} R_{12}^{*}}\left(\frac{1}{R_{1}^{*}}+\frac{1}{R_{2}^{*}}\right)},
$$

where $\operatorname{sh}(\beta)$ and $\operatorname{ch}(\beta)$ are the double sine function and double cosine function of parameter $\beta$, respectively.

2.2. Heat Transfer Model outside the Borehole. The finite-line source model in this study is based on the solution of the heat conduction exclusively in a homogeneous medium. This problem is solved by using the superposition principle to approximate the borehole as a finite-line source [29]. The model accounts for the influence between boreholes by an intricate superposition of numerical solutions with transient radial-axial heat conduction, one for each borehole. The response to any heat input can be calculated by devolving the heat injected into the ground by a series of step functions. The temperature response $(\theta)$ in the ground is then obtained from the sum of the time step responses and calculated by the following equation [30]: 


$$
\theta(r, z, \tau)=\sum_{i=1}^{n} \frac{q_{i}-q_{i-1}}{4 \lambda \pi} \int_{0}^{H}\left\{\frac{\operatorname{erfc}\left(\sqrt{r^{2}+(z-h)^{2}} / 2 \sqrt{\alpha\left(\tau_{n}-\tau_{i-1}\right) / h^{2}}\right)}{\sqrt{r^{2}+(z-h)^{2}}}-\frac{\operatorname{erfc}\left(\sqrt{r^{2}+(z+h)^{2}} / 2 \sqrt{\alpha\left(\tau_{n}-\tau_{i-1}\right) / h^{2}}\right)}{\sqrt{r^{2}+(z+h)^{2}}}\right\} \mathrm{d} h
$$

where the heat transfer rate per length in extracted or injected heat in time $\tau_{i}$ step is $q_{i}$, the radius $r$ and depth $z$ express the position of the aiming point, and $\alpha$ is the thermal diffusion coefficient. The temperature response at the boundary of the borehole $\left(\theta_{b}\right)$ is therefore

$$
\theta_{b}=\theta\left(r_{b}, z, \tau\right) .
$$

The temperature response $\theta_{b}$ presented above is for a single borehole. For the case of multiple boreholes with $\mathrm{n}$ GHEs, the total temperature response on the borehole wall or other position of a certain GHE, $\theta_{b, n}$, can be obtained by summing all the temperature responses [31]:

$$
\theta_{b, n}=\sum_{j=1}^{n} \theta\left(r_{j}, z, \tau\right) .
$$

The advantage of this model is that a spatial superimposition is used to account for the temperature responses for multiple boreholes. In addition, the sequential temporal superimposition is used to calculate the temperature response for any arbitrary heat injection or extraction, which can be decomposed into a set of single pulses. In other words, the overall temperature response of the GHEs to any heat injection or extraction at any time can be determined by the spatial and temporal superimpositions.

\section{Experimental System Description and Verification}

3.1. Experimental System. An experimental system of GHEs was set up in Beijing, China (altitude $40 \mathrm{~m}$, latitude $39.95^{\circ} \mathrm{N}$, longitude $116.35^{\circ} \mathrm{E}$ ). A schematic diagram of the experimental system is shown in Figure 2. The system consists of three components: (1) GHEs, (2) monitoring devices, and (3) thermostatic water bath as a heat source.

The GHE system consisted of four boreholes (Figure 2) that were drilled to an average depth of $70 \mathrm{~m}$. In the vertical heat exchanger, a U-tube of DN32 (nominal diameter) made from high-density polyethylene was buried in the ground, and the boreholes were back filled with grout.

The monitoring system included PT1000 temperature sensors (shown in Figure 3(a)) that were attached to the tube exterior wall at intervals of $10 \mathrm{~m}$ in each borehole. Two further temperature sensors were placed to allow the measurement of the GHE inlet fluid temperature $T_{\text {in }}$ and outlet fluid temperature $T_{\text {out }}$.

Figures 3(c) and 3(d) show digital photographs of soil samples taken during drilling. The installation of the water separator makes it possible to run each GHE individually or in combination.

Some boreholes were used to test the action of thermal fluids, while others were used to observe the surface temperature of inactive thermal fluids. The working fluid flow rates were measured by a metal tube flowmeter (Figure 4(e)). All measured variables were recorded using an Agilent data acquisition device every ten minutes as shown in Figure 4(f). Before installation of the sensor device, all temperature sensors were calibrated by a constant-temperature water bath with a water temperature accuracy of $0.1^{\circ} \mathrm{C}$.

A constant-temperature water bath, which provides a constant inlet temperature for the buried heated tube through insulated pipes, was used as the storage source. This instrument was equipped with an electric water heater and a rotary compressor. The maximum heating and cooling outputs were 9 and $5 \mathrm{~kW}$, respectively. The operating temperature of the water tank and the operation mass flow rate were both measured. The accuracy and measuring range of the sensor used in the experiment are shown in Table 1. To avoid freezing, the fluid was an antifreeze mixture of propylene glycol (20\%) and water.

In the heat storage experiment in this study, the surrounding borehole played a monitoring role when some of the GHEs were in action. From the autumn of 2015, a series of heat injection experiments were performed, as shown in Table 2. This study focused on the heat storage performance of GHEs under existing geological conditions, for which the performance of the GHEs is strongly dependent on the real-world situation. The test parameters of the experiment are shown in Table 3.

The recording of experimental data was completed in September 2016. The initial soil temperature was monitored without thermal disturbance from the heat source. The ground temperature profile in July 2015 is shown in Figure 5. The curve shows that the soil temperature was about $16^{\circ} \mathrm{C}$ and that the soil below $35 \mathrm{~m}$ was slightly cooler.

\subsection{Verification of the Simulation Result by Comparison with} Experimental Data. In the heat storage operation, verification of the simulation result against the experimental data consists of two aspects: the GHE fluid outlet temperature $(T)$ and the soil temperature variation caused by heat injection at different depths. Figure 4 shows the simulation and experimental results during the process of this operation.

In Experiment 1, Borehole 4\# is the working GHE and Borehole 2\# is used for observation. The two boreholes are spaced by a distance of $2.5 \mathrm{~m}$. The fluid inlet temperature $T_{\text {in }}$, fluid outlet temperatures $T_{\text {out }}$ (exp.) and $T_{\text {out }}$ (num.), 


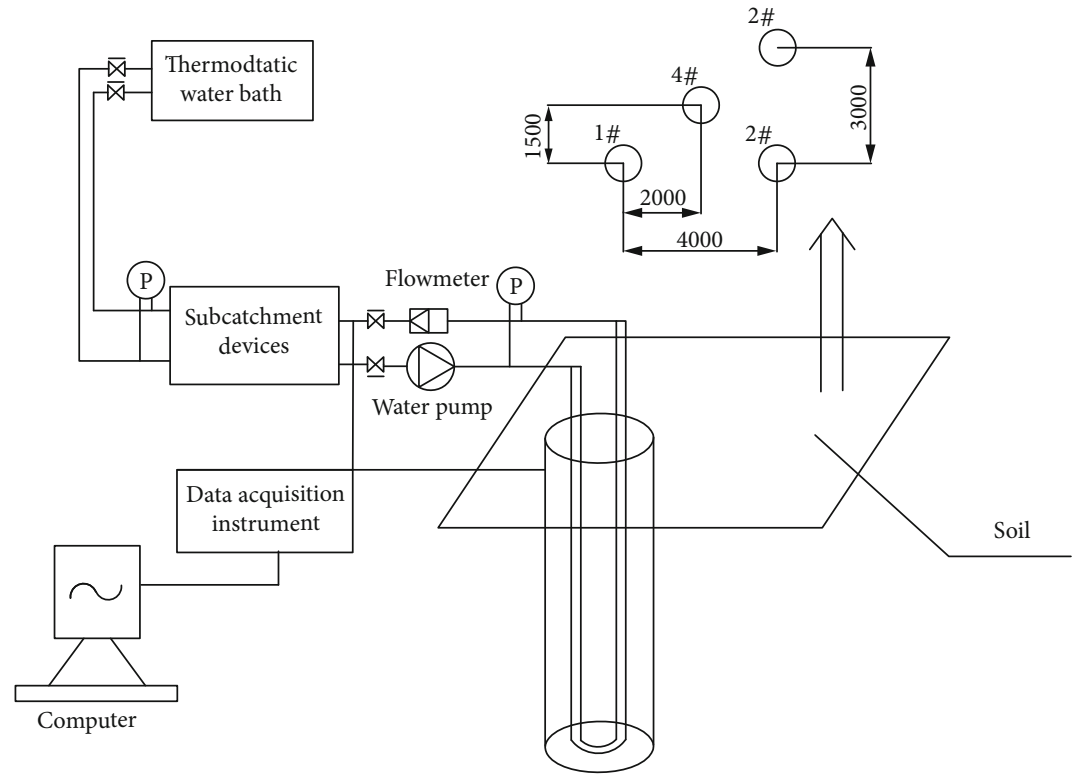

FIgURE 2: Schematic diagram of the experimental system.

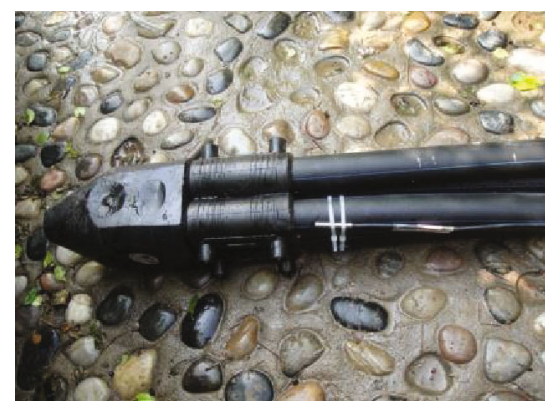

(a)

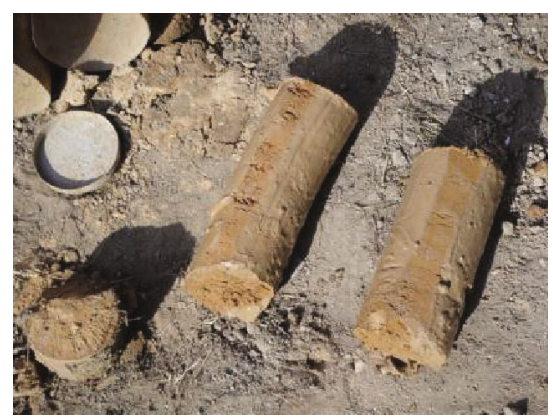

(c)

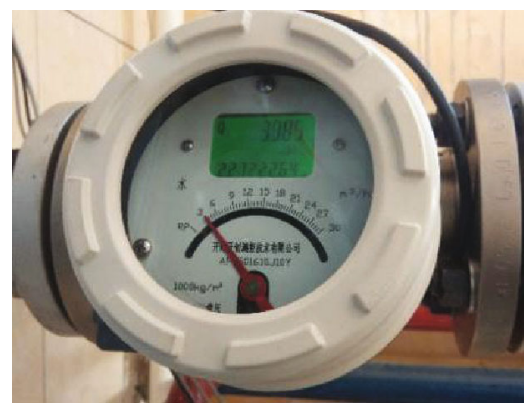

(e)

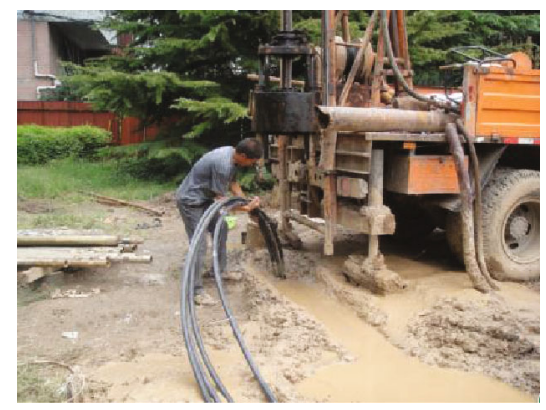

(b)

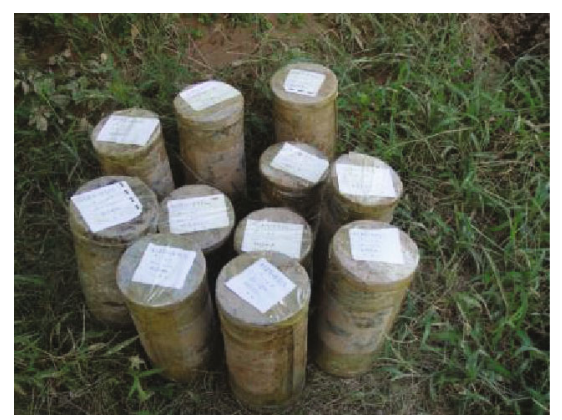

(d)

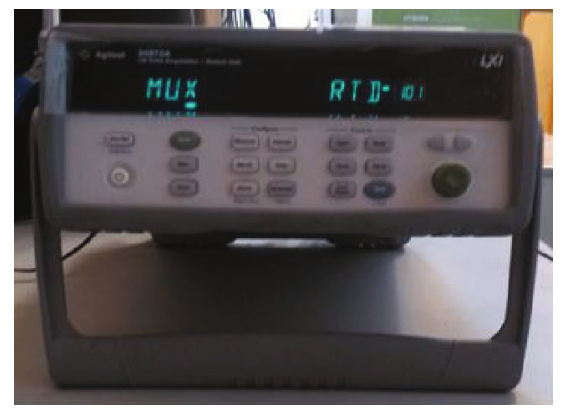

(f)

FIGURE 3: Digital photographs of the soil sampling process. 


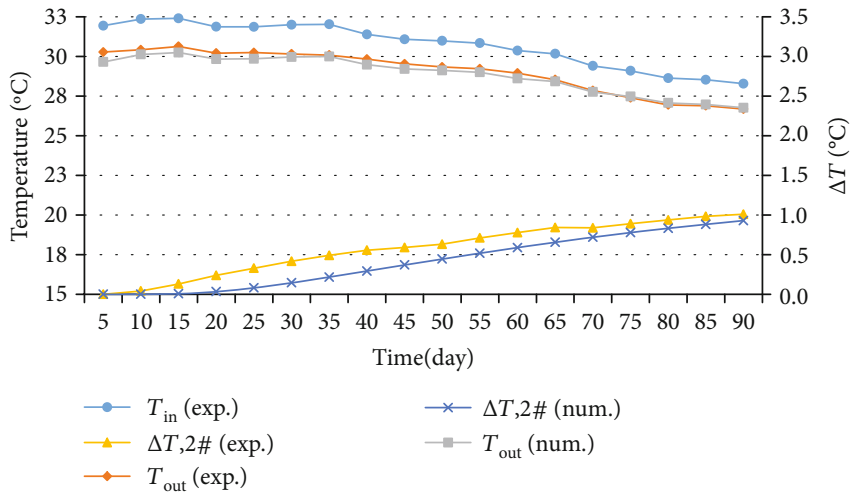

(a)

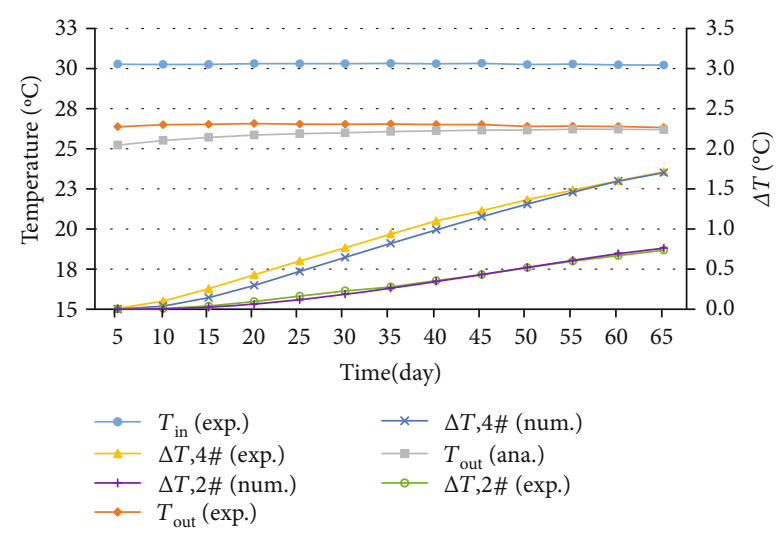

(b)

FIgURE 4: (a) Inlet and outlet temperatures in borehole 2\#. (b) Inlet and outlet temperatures in boreholes 2\# and 4\#.

TABLE 1: Accuracies and measuring ranges of the sensors in the experimental system.

\begin{tabular}{lcc}
\hline & Temperature & Volume flow rate \\
\hline Instrument measuring accuracy & $\pm 0.1^{\circ} \mathrm{C}$ & $\pm 0.5 \%$ \\
Measuring range & $-100-100^{\circ} \mathrm{C}$ & $1-30 \mathrm{~m}^{3} / \mathrm{h}$ \\
\hline
\end{tabular}

and soil temperature increases $\Delta T$ (exp.) and $\Delta T$ (num.) for the numerical model and experimental data are shown in Figure 4(a). The absolute error values of the outlet temperatures between the experimental and simulated results are less than $0.6^{\circ} \mathrm{C}$. The absolute error values of the $3 \#$ borehole temperature increases are less than $0.3^{\circ} \mathrm{C}$.

Figure 4(b) shows the validation of the inlet and outlet temperatures from the numerical model against those from the experimental data for the constant input test. Based on the experimental data from this constant input test, the inlet and outlet temperatures of the numerical model were verified.

In Experiment 2, the 1\# and 3\# boreholes are the working GHEs and the 2\# and 4\# boreholes are used for soil temperature observation. The inlet temperature $T_{\text {in }}$, outlet temperatures $T_{\text {out }}$ (exp.) and $T_{\text {out }}$ (num.), and soil temperature increases $\Delta T, 2 \#$ (exp.), $\Delta T, 2 \#$ (num.), $\Delta T, 4 \#$ (exp.), and $\Delta T$ ,4\# (num.) from the numerical model and experimental data are shown in Figure 4(b). The absolute error values of the outlet temperatures are between $0.13^{\circ} \mathrm{C}$ and $1.15^{\circ} \mathrm{C}$. The absolute error values for the $2 \#$ borehole and $4 \#$ borehole temperatures increase by $0.01^{\circ} \mathrm{C}$ to $0.13^{\circ} \mathrm{C}$ and by $-0.02^{\circ} \mathrm{C}$ to $0.04^{\circ} \mathrm{C}$, respectively.

The maximum relative percentage error for the soil simulation tests is relatively small, at $4.4 \%$ for all verifications. Maximum percentage error of $4.4 \%$ could explain the mismatch between the experimental and simulated results. The above discussion demonstrates the effectiveness of the developed model.

\section{Case Study}

Different combinations of solar-assisted auxiliary heat source and conventional GSHP can lead to different soil tempera- ture properties and system efficiencies. The main objective of this study is to analyze the performance of SA-GSHP systems and to optimize the solar collector size for SA-GSHP systems operating in cold regions. The main components of the SA-GSHP system are the heat pump, borehole heat exchangers, solar collectors, and storage tank. The overall system was dynamically simulated in the TRNSYS software package. The GHEs validated above and experimental data were modeled in MATLAB and linked to the main TRNSYS project. Other components (such as the heat loads, solar thermal collectors, storage tank, weather calculator, valves, pumps, and controllers) were simulated using TRNSYS built-in models. When the location characterized by a cold climate was confirmed, the building load profile was calculated. That load was then used to simulate the plant system, which consists of a GSHP coupled with or without solar thermal collectors. The building and its characteristics were the same for all simulations in each of the three regions. TRNSYS can be used to study each subsystem of the whole power plant in detail and consider the actual coupling and control strategy in a step-by-step manner. The proposed system is shown in Figure 6. The thermal plant system was initially designed by selecting the surface size of the solar thermal collectors, the volume of the storage tank, and the total borehole length.

4.1. Heating Load. The cities of Beijing, Harbin, and Zhengzhou in China are regions in which GSHP systems cause cold accumulation and decreased soil temperature. These three regions are characterized by different climates and were used for analysis [32], which is appropriate because SA-GSHP systems are aimed at meeting building heating loads. The ambient dry-bulb temperature and wet-bulb temperature (i.e., humidity) for these three regions are shown in the left diagrams of Figure 7 . The hourly heating and cooling loads for a $2000 \mathrm{~m}^{2}$ residential building are simulated using the DeST software package, and the results are shown in the right diagrams of Figure 7. Figures $7(a)-7$ (c) show the peak heating loads for the Beijing, Harbin, and Zhengzhou regions when the building is used for residential heating.

4.2. Heat Pump. The heat pump is connected to the GHEs on the evaporator side and connected to the building on the 
TABLE 2: Experimental conditions.

\begin{tabular}{lccccc}
\hline Experiment no. & $\begin{array}{c}\text { Continuous experiment } \\
\text { period }\end{array}$ & $\begin{array}{c}\text { Borehole } \\
\text { in action }\end{array}$ & Operation mode & Flow rate $(\mathrm{kg} / \mathrm{s})$ & $\begin{array}{c}\text { Average inlet } \\
\text { temperature }\left({ }^{\circ} \mathrm{C}\right)\end{array}$ \\
\hline 1 & 16 Aug. 2015-15 Oct. 2015 & $\# 4$ & $\begin{array}{c}\text { Single-U heat injection } \\
\text { (storage mode) }\end{array}$ & 0.34 & 30.3 \\
2 & 14 Jul. 2016-17 Sep. 2016 & $\# 1$ and \#3 & Single-U heat injection (storage mode) & 0.34 & 30.3 \\
\hline
\end{tabular}

TABLE 3: Experimental parameters of the GHEs.

\begin{tabular}{lc}
\hline Parameter & Value \\
\hline Grout conductivity & $1.7 \mathrm{~W} /(\mathrm{m} \cdot \mathrm{K})$ \\
Soil conductivity & $1.43 \mathrm{~W} /(\mathrm{m} \cdot \mathrm{K})$ \\
Pipe conductivity & $0.39 \mathrm{~W} /(\mathrm{m} \cdot \mathrm{K})$ \\
Soil density & $1900 \mathrm{~kg} / \mathrm{m}^{3}$ \\
Soil specific capacity & $2.086 \mathrm{~kJ} /\left(\mathrm{kg} \cdot{ }^{\circ} \mathrm{C}\right)$ \\
Working fluid capacity & $3.7 \mathrm{~kJ} /\left(\mathrm{kg} \cdot{ }^{\circ} \mathrm{C}\right)$ \\
Working fluid density & $1027 \mathrm{~kg} / \mathrm{m}^{3}$ \\
Test flow rates & $1.224 \mathrm{~m}^{3} / \mathrm{h}$ \\
\hline
\end{tabular}

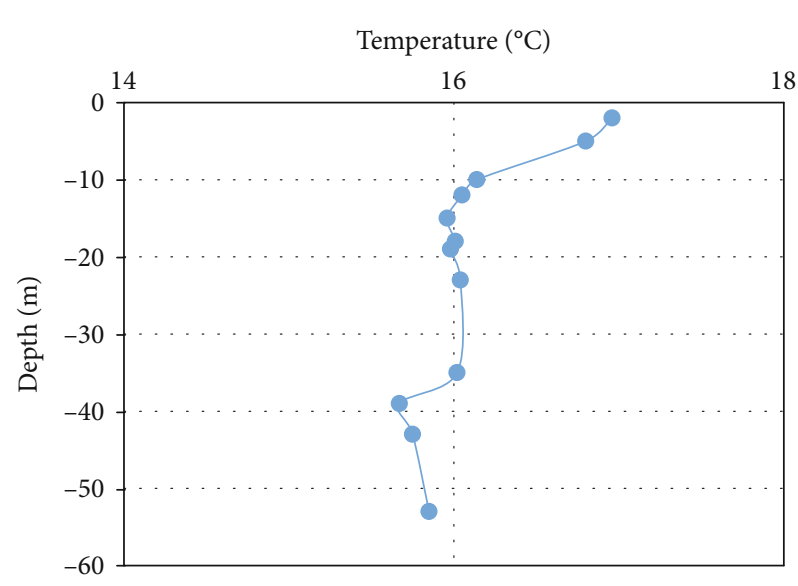

FIGURE 5: Plot of the initial soil temperature with depth.

condenser side. The type 668 models used a water-to-water heat pump that can operate with any kind of liquid (not necessarily water). Thus, the heat pump can be used as a geothermal heat pump if coupled with a GHE. This component reads an external file prepared by the user, consisting of the load, source temperature, and COP of the heat pump. These data are available from the manufacturer's catalog. Table 4 shows the data file used for the GSHP heating capacity of $44 \mathrm{~kW}$, which can satisfy the peak heating load and peak cooling load. The number of heat pumps in different regions was adjusted according to the maximum load. Specifically, two heat pumps were used in the Beijing region, three were used in the Harbin region, and one was used in the Zhengzhou region.

These values are a function of the source and load temperatures. All the data were processed, and the simulation results show the COP, heating capacity, and return temperature from the evaporator to the storage tank (on the heat source side) for each time step.
In the previous section, the GHE model was validated by comparing simulated results with the experimental data. In the current section, the calculation code implemented in MATLAB was linked to the main TRNSYS project and integrated with the other components. The total length of the GHEs required to meet the heating and cooling loads is the main parameter in the GSHP design process. In typical ground conditions for a borehole heat exchanger, the borehole length is sized for a heat extraction rate $\left(q_{\text {design }}\right)$ of $50 \mathrm{~W} / \mathrm{m}$ of borehole length [32]. Consequently, the GHE's total length can be calculated by

$$
\left\{\begin{array}{l}
L_{\text {heating }}=\frac{q_{\text {heating,max }}}{q_{\text {design }}} \times\left(1-\frac{1}{\mathrm{COP}_{\text {heating }}}\right), \\
L_{\text {cooling }}=\frac{q_{\text {cooling,max }}}{q_{\text {design }}} \times\left(1+\frac{1}{\mathrm{COP}_{\text {heating }}}\right), \\
L=\operatorname{Max}\left\langle L_{\text {heating }}, L_{\text {cooling }}\right\rangle,
\end{array}\right.
$$

where $q_{\text {heating,max }}$ and $q_{\text {cooling,max }}$ are the peak heating load and peak cooling load, respectively; $\mathrm{COP}_{\text {heating }}$ and $\mathrm{COP}_{\text {cooling }}$ are the COPs under heating and cooling conditions, respectively; and $L_{\text {heating, }} L_{\text {cooling }}$ and $L$ are the designed GHE total length under heating conditions, cooling conditions, and the final selected GHE length, respectively. The characteristics of the borehole GHEs and the thermal properties of the ground are summarized in Table 5. The initial soil temperature was set to $16^{\circ} \mathrm{C}$, as shown in Figure 5 .

4.3. Solar Collectors. The heat from solar radiation was captured by solar thermal collectors installed on the southfacing roof at a $45^{\circ}$ slope. The properties of this system are summarized in Table 6. The heat-carrier fluid of the solar thermal collectors is a $50 \%$ propylene glycol in water, and its mass flow rate (pump no. 1 in Figure $1(\mathrm{a})$ ) is $1.65 \mathrm{~kg} / \mathrm{s}$. The thermal behavior of the solar thermal collectors was simulated by the Type 1c function of the TRNSYS tool, which models the thermal performance of flat-plate solar collectors utilizing the $g_{0}, a_{1}$, and $a_{2}$ coefficients, as declared by the manufacturer. The thermal performance of the collector array is determined by the number of modules in series and the characteristics of each module. The effects of off-normal solar incidence radiation are evaluated by incidence angle modifiers which are read from an external data file as a function of the incidence angle. In the simulation, the surface areas of solar collectors in the different 


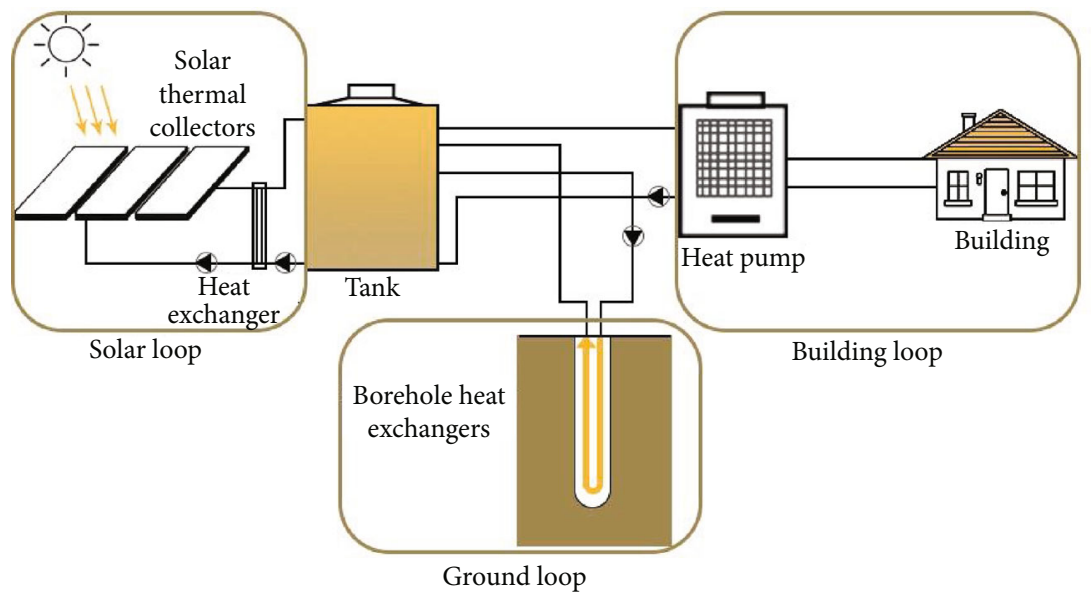

Figure 6: Proposed system involving GSHP and solar thermal collectors.

regions need to be calculated. This is achieved using the following equations:

$$
\begin{aligned}
q_{\text {gap }}= & q_{\text {heating,total }} \times\left(1-\frac{1}{\mathrm{COP}_{\text {heating }}}\right) \\
& -q_{\text {cooling,total }} \times\left(1+\frac{1}{\mathrm{COP}_{\text {cooling }}}\right), \\
A= & \frac{k_{c} \times f \times q_{\text {gap }}}{90 \times 3600 \times S_{y} \times U \times \Delta t},
\end{aligned}
$$

where $f$ is the solar energy guarantee rate (\%); $k_{c}$ is the time-varying coefficient of solar radiation illumination, which is 1.5-1.8 (this benefits the utilization of solar energy but increases the cost); $S_{y}$ is the local average daily sunshine hours per year (h); $U$ is the heat transfer coefficient of the heat exchanger, which is determined according to the technical parameters of the heat exchanger; $A$ is the heat exchanger area $\left(\mathrm{m}^{2}\right)$; and $q_{\text {gap }}$ is the average daily heat supply of the solar heating system during the heating season $(\mathrm{kW})$ [26].

4.4. Heat Storage Tank. Heat storage is important in solar systems to compensate for time differences between the availability of the heat source and the availability of the heating demand. A stratified fluid storage tank was considered in the current study. The storage tank was modeled using the TRNSYS software Type $4 \mathrm{~d}$ function [33], based on the assumption that the tank can be divided into $N$ fully mixed equal subvolumes. The tank is also equipped with a pressure relief valve, to consider boiling effects. The model also considers the energy released by the fluid flowing through the valve, whereas the corresponding loss of mass is neglected. This subroutine simulates a fluid-filled constant-volume storage tank and simulates a cylindrical tank with a vertical configuration. The fluid in the storage tank interacts with the fluid that may exist in the heat exchanger, with the ambient air, and with flow streams that pass into and out of the storage tank [34].
4.5. Control Strategy. In the simulation, the imbalance efficiency need to be calculated. This is achieved using the following equations:

$$
\eta_{\mathrm{ie}}=\left|\frac{Q_{\text {heating,total }}-Q_{\text {cooling,total }}}{Q_{\text {heating,total }}}\right| \text {, }
$$

where $\eta_{\mathrm{ie}}$ is the imbalance efficiency, $Q_{\text {heating,total }}$ is the sum of the energy storage during the ten years, and $Q_{\text {cooling,total }}$ is the sum of the energy absorbed during the ten years.

In this paper, a method for optimization of the area of the solar collector for a seasonal heat storage solar ground source heat pump system is proposed. The specific calculation steps are shown in Figure 8.

The initial solar thermal collector area is first put into the seasonal heat storage SA-GSHP system and it is determined whether the efficiency is less than $1 \%$. If $Q_{\text {heating,total }}<$ $Q_{\text {cooling,total }}$ and the efficiency are greater than $1 \%$, the area will increase by $5 \%$. Otherwise, it should be reduced by $5 \%$ to obtain a new solar thermal collector area, and then simulation calculation can be carried out.

Figure 9 shows the control strategy. In the heating season, if the average temperature of the building is lower than $18^{\circ} \mathrm{C}$, the heat pump is turned on. When the temperature is higher than $24^{\circ} \mathrm{C}$, the heat pump is turned off.

In the cooling season, if the average temperature of the building is lower than $18^{\circ} \mathrm{C}$, the heat pump is turned off. When the temperature exceeds $24^{\circ} \mathrm{C}$, the heat pump is turned on.

In the nonheating (cooling) season, the heat exchanger of the solar energy system unit is connected with the GHE circuit for heat storage.

\section{Simulation Results and Discussion}

Based on the model discussed in the previous section, case studies were conducted in Beijing, Harbin, and Zhengzhou. The main purpose of the long-term simulation was to compare the performance of the proposed SA-GSHP combined system with that of the conventional GSHP system. 

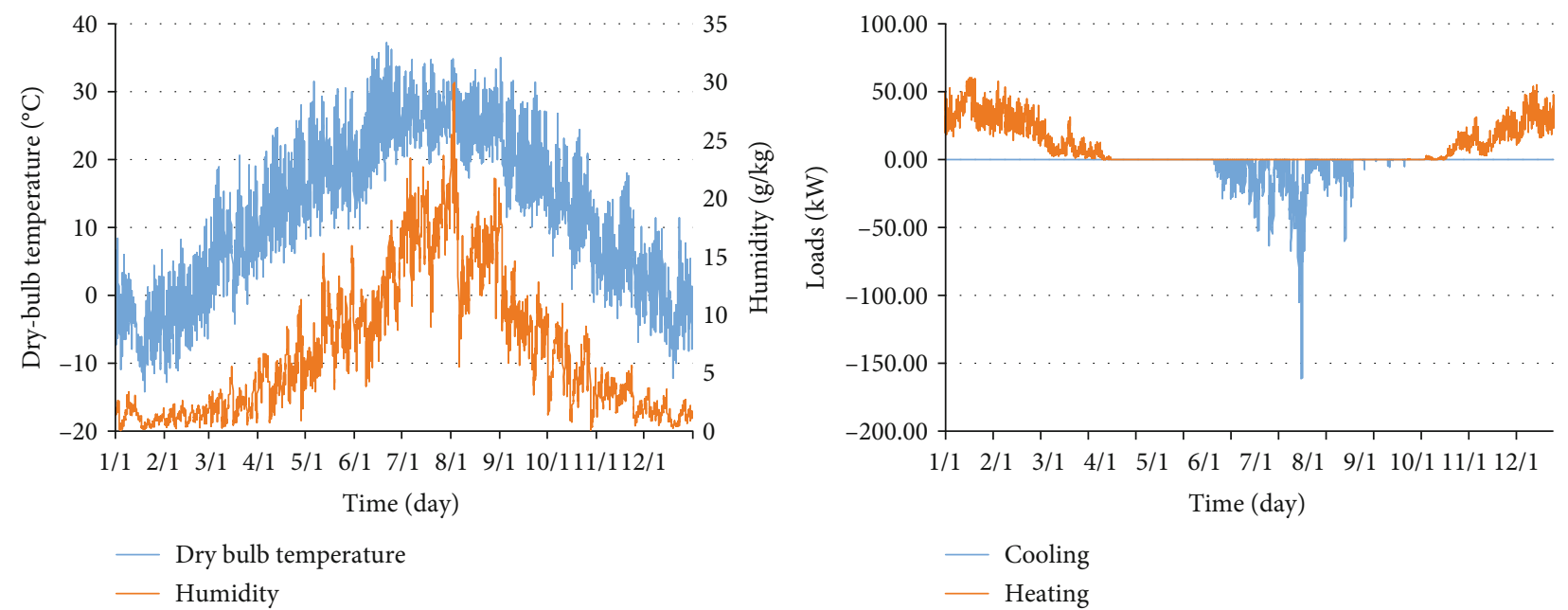

- Dry bulb temperature

Heating

(a) Case 1 (Beijing)

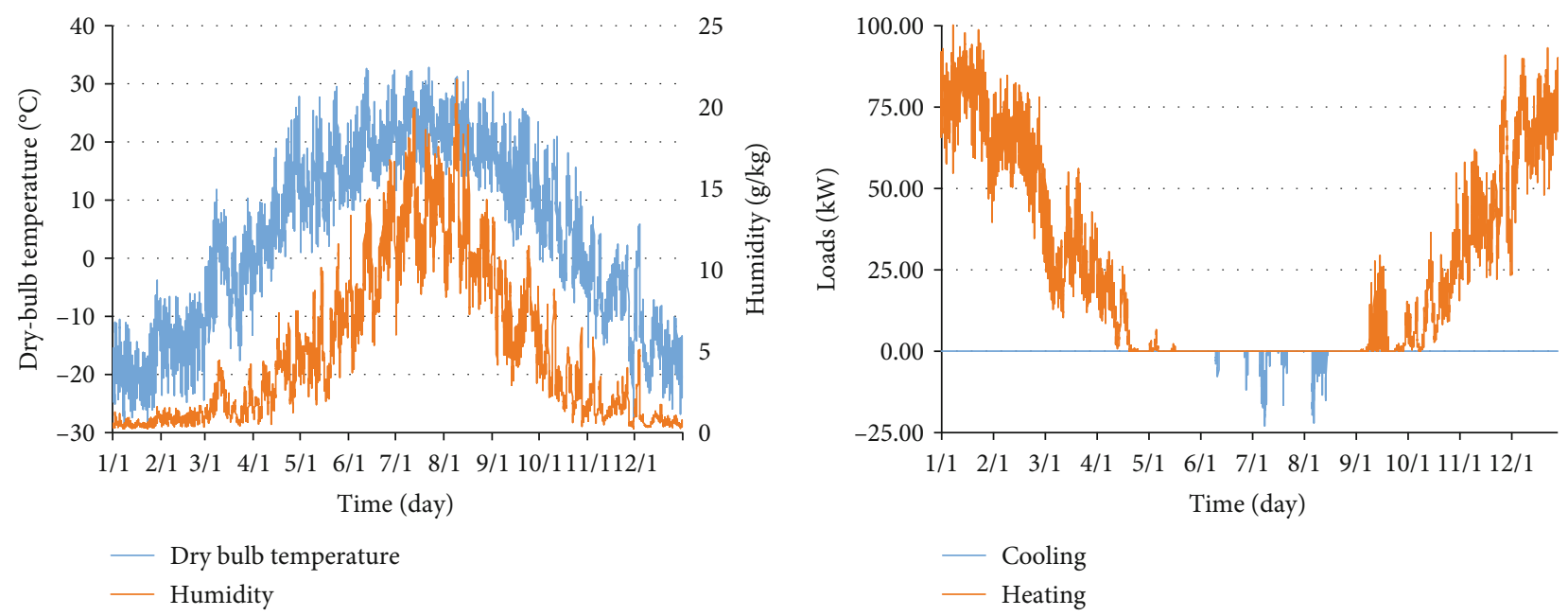

(b) Case 2 (Harbin)
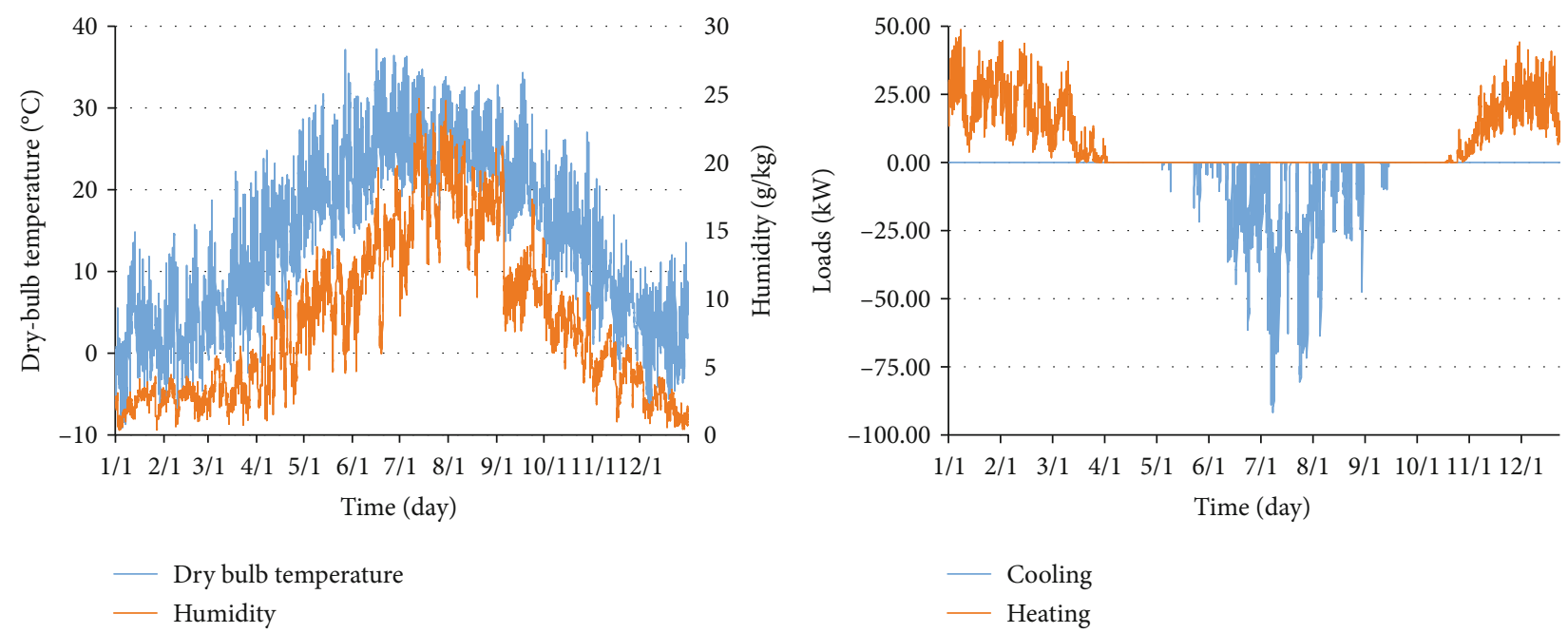

(c) Case 3 (Zhengzhou)

Figure 7: Climate characteristics and dynamic building loads for different uses in the Beijing, Harbin, and Zhengzhou regions. 
TABLE 4

(a) Cooling characteristics of the heat pump

\begin{tabular}{|c|c|c|c|c|c|c|c|c|}
\hline \multirow{2}{*}{$T_{\text {source }}\left({ }^{\circ} \mathrm{C}\right)$} & \multicolumn{2}{|c|}{0} & \multicolumn{2}{|c|}{6} & \multicolumn{2}{|c|}{12} & \multicolumn{2}{|c|}{18} \\
\hline & Power & $\mathrm{COP}$ & Power & $\mathrm{COP}$ & Power & $\mathrm{COP}$ & Power & $\mathrm{COP}$ \\
\hline \multicolumn{9}{|l|}{$T_{\text {load }}\left({ }^{\circ} \mathrm{C}\right)$} \\
\hline 5 & 17.43 & 2.66 & 19.64 & 2.70 & 21.85 & 2.78 & 24.05 & 2.84 \\
\hline 10 & 17.49 & 2.83 & 19.33 & 2.87 & 21.19 & 2.90 & 23.03 & 2.93 \\
\hline 20 & 15.82 & 3.43 & 17.40 & 3.50 & 17.92 & 3.56 & 21.56 & 3.63 \\
\hline 29 & 14.31 & 3.80 & 15.92 & 3.85 & 17.52 & 3.90 & 19.13 & 3.95 \\
\hline 32 & 14.24 & 3.98 & 15.68 & 4.03 & 17.13 & 4.08 & 19.57 & 4.13 \\
\hline 38 & 13.32 & 4.30 & 14.66 & 4.33 & 15.99 & 4.36 & 17.33 & 4.40 \\
\hline
\end{tabular}

(b) Heating characteristics of the heat pump

\begin{tabular}{|c|c|c|c|c|c|c|c|c|}
\hline \multirow{2}{*}{$T_{\text {load }}\left({ }^{\circ} \mathrm{C}\right)$} & \multicolumn{2}{|c|}{35} & \multicolumn{2}{|c|}{40} & \multicolumn{2}{|c|}{45} & \multicolumn{2}{|c|}{50} \\
\hline & Power & $\mathrm{COP}$ & Power & $\mathrm{COP}$ & Power & $\mathrm{COP}$ & Power & COP \\
\hline \multicolumn{9}{|l|}{$T_{\text {source }}\left({ }^{\circ} \mathrm{C}\right)$} \\
\hline-4 & 18.72 & 2.52 & 18.22 & 2.80 & 17.72 & 3.08 & 17.21 & 3.36 \\
\hline 0 & 22.37 & 2.71 & 21.77 & 3.00 & 21.17 & 3.29 & 20.57 & 3.58 \\
\hline 4 & 26.02 & 2.90 & 25.32 & 3.20 & 24.63 & 3.50 & 23.93 & 3.80 \\
\hline 10 & 30.27 & 3.37 & 29.46 & 3.69 & 28.66 & 4.00 & 27.85 & 4.32 \\
\hline 20 & 39.22 & 4.24 & 38.17 & 4.60 & 37.12 & 4.96 & 36.07 & 4.32 \\
\hline 29 & 43.71 & 4.82 & 42.55 & 5.20 & 41.39 & 4.58 & 40.23 & 4.96 \\
\hline
\end{tabular}

TABLE 5: Characteristics of the double U-tube heat exchanger.

\begin{tabular}{lcc}
\hline Pipe & & \\
\hline Material & $\mathrm{W} /(\mathrm{m} \cdot \mathrm{K})$ & $\begin{array}{c}\text { High-density } \\
\text { polyethylene }\end{array}$ \\
$\begin{array}{l}\text { Thermal conductivity } \\
\text { Outside diameter }\end{array}$ & 0.4 \\
$\begin{array}{l}\text { Inside diameter } \\
\text { Number of pipes }\end{array}$ & $\mathrm{mm}$ & 26.0 \\
$\begin{array}{l}\text { Distance between pipes } \\
\text { (center to center) }\end{array}$ & $\mathrm{mm}$ & 32.0 \\
$\begin{array}{l}\text { Borehole diameter } \\
\text { Connection between the } \\
\text { two U tubes }\end{array}$ & $\mathrm{mm}$ & 50.0 \\
$\begin{array}{l}\text { Grout thermal conductivity } \\
\text { Heat-carrier fluid }\end{array}$ & $\mathrm{W} /(\mathrm{m} \cdot \mathrm{K})$ & 140.0 \\
& & $\begin{array}{c}\text { Parallel } \\
\text { propylene glycol }\end{array}$ \\
\hline
\end{tabular}

The imbalance efficiency in the three regions was simulated, as shown in Figure 10. The imbalance efficiency in the three places is obviously different from that shown in the figure.

In the Beijing region, the $Q_{\text {heating,total }}$ is $4.99 \times 10^{8} \mathrm{kWh}$, the $Q_{\text {cooling,total }}$ is $11.2 \times 10^{8} \mathrm{kWh}$, and the imbalance efficiency is $55 \%$. In the Harbin region, the $Q_{\text {heating,total }}$ is $14.3 \times 10^{8} \mathrm{kWh}$, the $Q_{\text {cooling,total }}$ is $2.98 \times 10^{8} \mathrm{kWh}$, and the imbalance efficiency is $79 \%$. In the Zhengzhou region, the
$Q_{\text {heating,total }}$ is $9.63 \times 10^{8} \mathrm{kWh}$, the $Q_{\text {cooling,total }}$ is $5.97 \times 10^{8}$ $\mathrm{kWh}$, and the imbalance efficiency is $38 \%$.

The temperature of soil in the three regions was simulated, as shown in Figure 11. The $x$-axis represents time in hours, and the $y$-axis represents soil temperature.

The soil temperatures in the different regions all show significant decreases, especially in the Harbin region where the soil is needed to store heat [35].

In the Beijing region, for the conventional GSHP system, the annual average soil temperature decreases from $15.8^{\circ} \mathrm{C}$ to $8.5^{\circ} \mathrm{C}$ during ten years of operation. As heat extracted by the heat pump unit from the ground decreases yearly, the rate of reduction in the average soil temperature slows. For the SA-GSHP system, the soil temperature fluctuates between $13.1^{\circ} \mathrm{C}$ and $17.9^{\circ} \mathrm{C}$.

In the Harbin region, for the conventional GSHP system, the annual average soil temperature decreases from $10.6^{\circ} \mathrm{C}$ to $3.1^{\circ} \mathrm{C}$ during the ten years of operation. For the SA-GSHP system, the soil temperature fluctuates between $8.2^{\circ} \mathrm{C}$ and $12.5^{\circ} \mathrm{C}$. The annual average soil temperature remains stable over the decade.

In the Zhengzhou region, for the conventional GSHP system, the annual average soil temperature decreases from $18.3^{\circ} \mathrm{C}$ to $14.1^{\circ} \mathrm{C}$ during the ten years of operation. For the SA-GSHP system, the soil temperature fluctuates between $10.9^{\circ} \mathrm{C}$ and $16.2^{\circ} \mathrm{C}$.

Figure 12 shows the ten-year trend in dynamic quality during heating for the GSHP and SA-GSHP systems. The $x$-axis represents time in hours, and the $y$-axis represents COP. 
Table 6

(a) Characteristics of the solar thermal collectors in the Beijing region

\begin{tabular}{lcc}
\hline Total area of solar thermal collectors & $\mathrm{m}^{2}$ & 300.58 \\
Area of the single collector & $\mathrm{m}^{2}$ & 2.26 \\
Number of collectors & & 133 \\
Number of collectors in series & & 6 \\
$\eta_{0}$ & $\mathrm{~W} /\left(\mathrm{m}^{2} \cdot \mathrm{K}\right)$ & 0.768 \\
$\alpha_{1}$ & $\mathrm{~W} /\left(\mathrm{m}^{2} \cdot \mathrm{K}\right)$ & 3.4 \\
$\alpha_{2}$ & & 0.0089 \\
Heat-carrier fluid & & $\begin{array}{c}50 \% \text { mixture } \\
\text { of propylene } \\
\text { glycol }\end{array}$ \\
\hline
\end{tabular}

(b) Characteristics of the solar thermal collectors in the Harbin region

\begin{tabular}{lcc}
\hline Total area of solar thermal collectors & $\mathrm{m}^{2}$ & 800.04 \\
Area of the single collector & $\mathrm{m}^{2}$ & 2.26 \\
Number of collectors & & 354 \\
Number of collectors in series & & 6 \\
$\eta_{0}$ & $\mathrm{~W} /\left(\mathrm{m}^{2} \cdot \mathrm{K}\right)$ & 0.768 \\
$\alpha_{1}$ & $\mathrm{~W} /\left(\mathrm{m}^{2} \cdot \mathrm{K}\right)$ & 3.4 \\
$\alpha_{2}$ & & $\begin{array}{c}0.0089 \\
50 \% \text { mixture } \\
\text { of propylene } \\
\text { Heat-carrier fluid }\end{array}$ \\
& & glycol \\
\hline
\end{tabular}

(c) Characteristics of the solar thermal collectors in the Zhengzhou region

\begin{tabular}{lcc}
\hline Total area of solar thermal collectors & $\mathrm{m}^{2}$ & 201.14 \\
Area of the single collector & $\mathrm{m}^{2}$ & 2.26 \\
Number of collectors & & 177 \\
Number of collectors in series & & 6 \\
$\eta_{0}$ & $\mathrm{~W} /\left(\mathrm{m}^{2} \cdot \mathrm{K}\right)$ & 0.768 \\
$\alpha_{1}$ & $\mathrm{~W} /\left(\mathrm{m}^{2} \cdot \mathrm{K}\right)$ & 3.4 \\
$\alpha_{2}$ & & $\begin{array}{c}0.0089 \\
50 \% \text { mixture } \\
\text { of propylene } \\
\text { glycol }\end{array}$ \\
Heat-carrier fluid & & \\
& &
\end{tabular}

In the Beijing region, the average annual COP in winter for the first year is 3.9, while in the tenth year, it is 2.9 and the COP decreases by $23 \%$. For the SA-GSHP system, the relatively stable soil temperature results in the average annual COP of the heat pump unit remaining at around 3.9 over the ten years.

In the Harbin region, the average annual COP in the first year is 3.7, while in the tenth year, it is 2.0 and the COP decreases by $46 \%$. For the SA-GSHP system, the annual average COP of the heat pump unit remains at around 3.6 over the ten years, because of the relatively stable soil temperature.

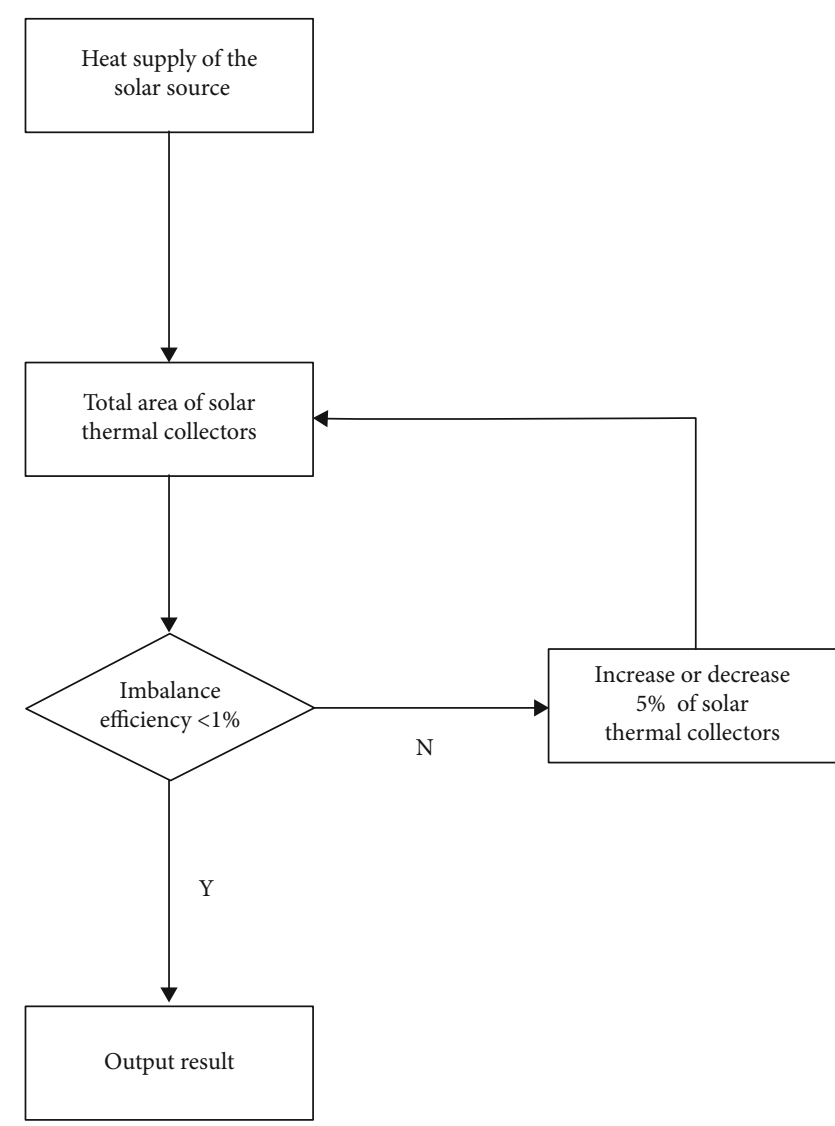

Figure 8: Optimization of solar collector area.

In the Zhengzhou region, the average annual COP in the first year is 3.8, while in the tenth year, it is 3.4 and the COP decreases by $11 \%$. For the SA-GSHP system, the relatively stable soil temperature results in the average annual COP of the heat pump unit remaining at around 3.8 over ten years.

Figure 13 shows the first year and the tenth year during heating for the GSHP and SA-GSHP systems. The $x$-axis represents time in hours, and the $y$-axis represents the on/off state of the heat pump.

In the Beijing region, as the soil temperature decreases, the operating time of the heat pump unit of the conventional GSHP system increases from 2626 hours in the first year to 2767 hours in the tenth year. In contrast, the heat pump unit of the SA-GSHP system has a running time of approximately 2581 hours per year. The operating time of the heat pump unit of the SA-GSHP system is 45 hours lower in the first year and 186 hours lower in the tenth year, when compared with the conventional GSHP system. The total operating time over ten years of the heat pump units in the GSHP and SA-GSHP systems is 27,120 and 25,917 hours, respectively.

In the Harbin region, the operating time of the heat pump unit for the traditional GSHP system increases from 2855 hours in the first year to 3221 hours in the tenth year. In contrast, the heat pump unit of the SA-GSHP system operates for approximately 2784 hours per year. The operating time of the heat pump unit for the SA-GSHP system decreases by 71 hours in the first year and by 437 hours in the tenth year, compared with the conventional GSHP 


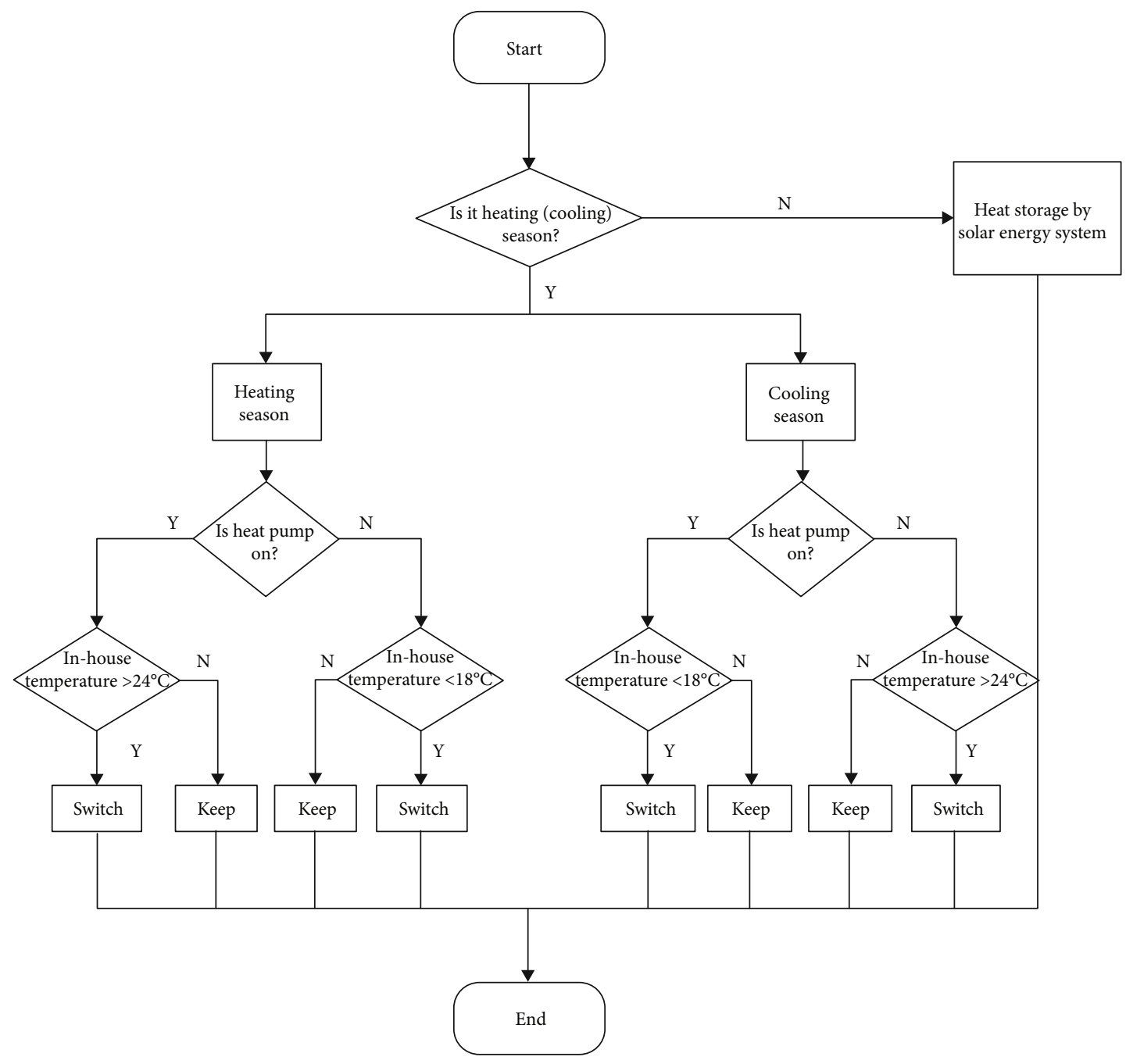

Figure 9: Control strategy of the system.

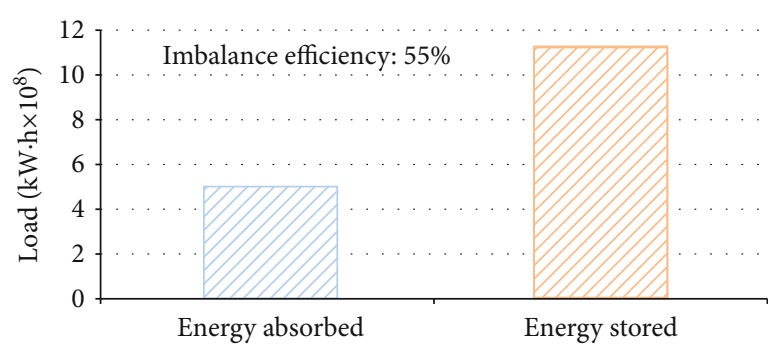

(a) Case 1 (Beijing)

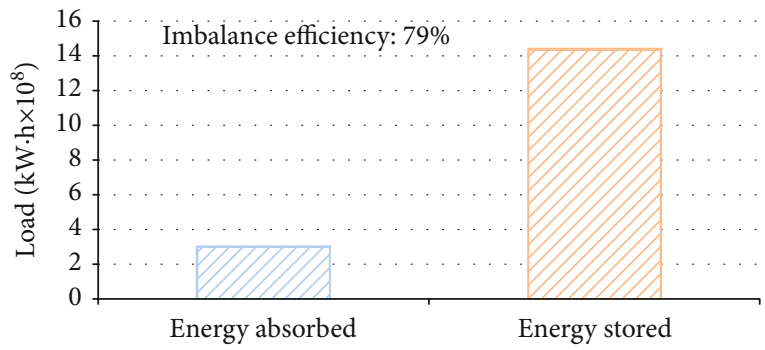

(b) Case 2 (Harbin)

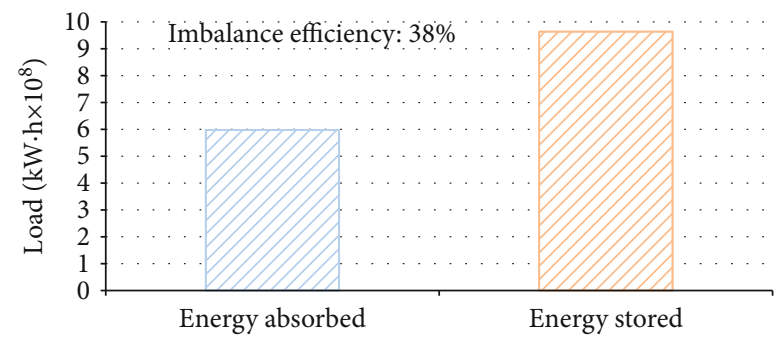

(c) Case 3 (Zhengzhou)

Figure 10: Imbalance efficiency in the Beijing, Harbin, and Zhengzhou regions. 


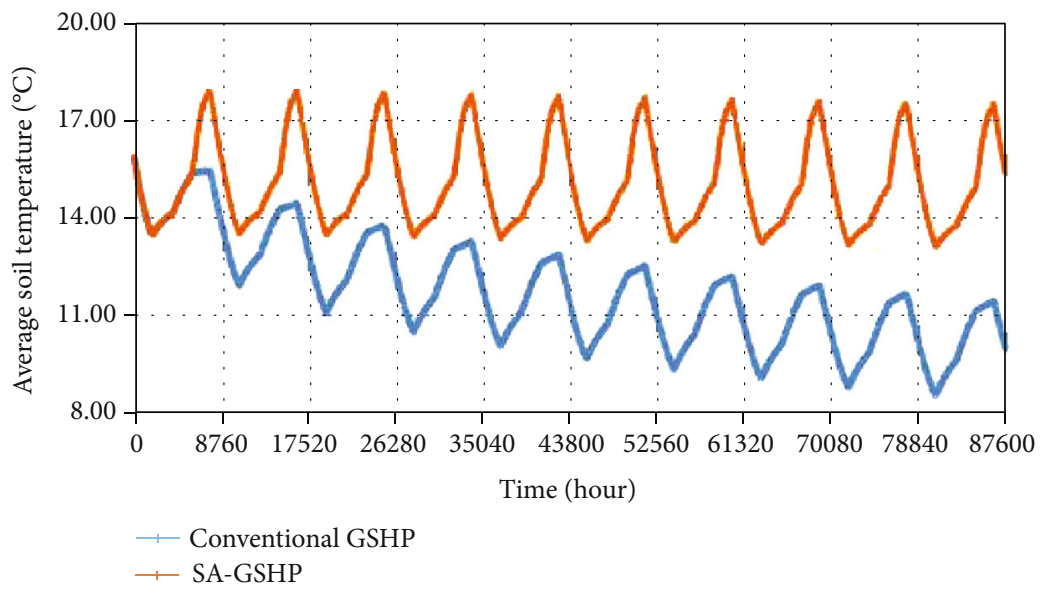

(a) Case 1 (Beijing)

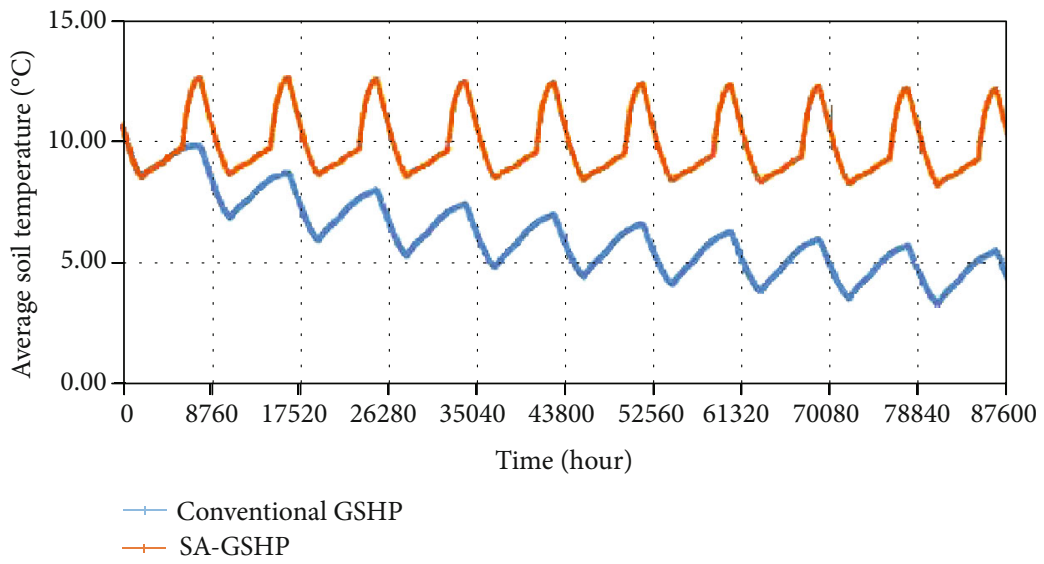

(b) Case 2 (Harbin)

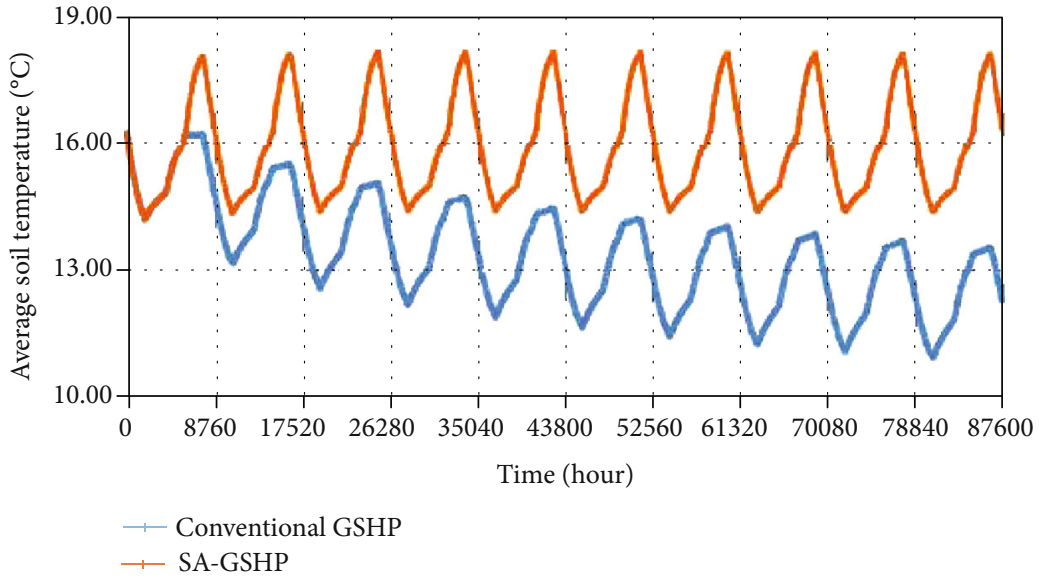

(c) Case 3 (Zhengzhou)

FIGURE 11: Soil temperature in the Beijing, Harbin, and Zhengzhou regions.

system. The total operating time over ten years of the heat pump units for the GSHP and SA-GSHP systems is 29,433 and 27,853 hours, respectively.

In the Zhengzhou region, the operating time of the heat pump unit for the traditional GSHP system increases from 2379 hours in the first year to 2443 hours in the tenth year. In contrast, the heat pump unit of the SAGSHP system operates for approximately 2355 hours per year. The total operating time over 10 years of the heat pump units for the GSHP and SA-GSHP systems is 24,183 and 23,535 hours, respectively. There is not much difference between the two systems.

Among the three cities, they have different building loads. Harbin has the smallest cooling loads in summer and the largest heating loads in winter. So the problem of soil cold accumulation is very serious. Compared with Harbin, Beijing 


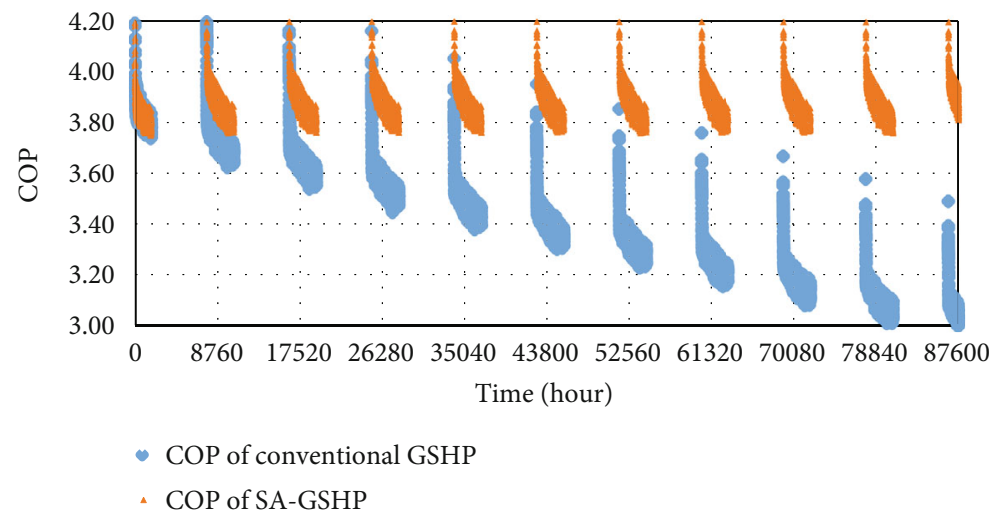

(a) Case 1 (Beijing)

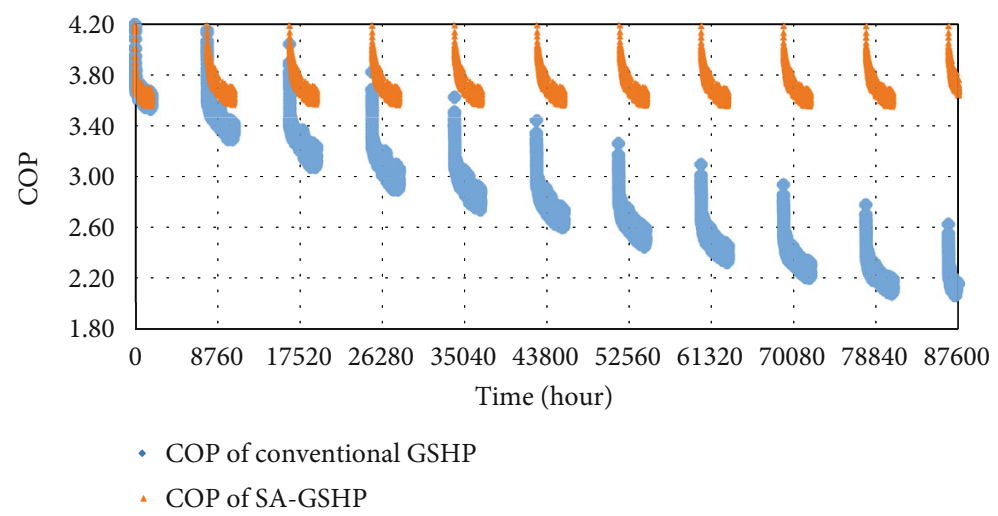

(b) Case 2 (Harbin)

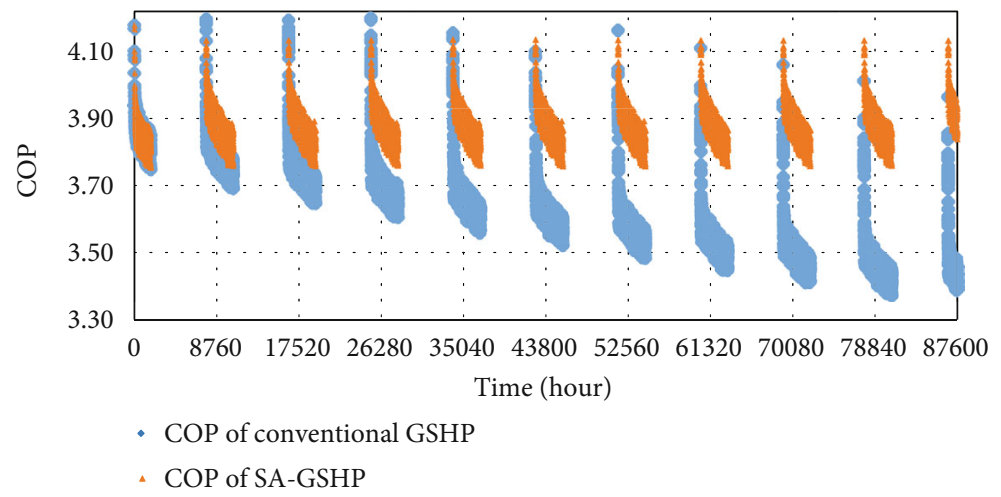

(c) Case 3 (Zhengzhou)

FIGURE 12: Ten-year trend in dynamic quality during heating for the GSHP and SA-GSHP systems.

has more cooling loads in summer and less heating loads in winter. Zhengzhou has the largest cooling loads in summer and the smallest heating loads in winter; the soil temperature drops less and the system is relatively stable.

\section{Conclusion}

This paper reports a method for analyzing the imbalance efficiency, specifically, to determine whether a GSHP system requires additional heat storage. Three typical cities, Beijing, Harbin, and Zhengzhou, are selected from the cold region, the severe cold region, and the hot summer and the cold win- ter region for simulation, and the performance and parameter variations of GSHP systems are analyzed.

It was found that the imbalance efficiency of Beijing, Harbin, and Zhengzhou is $55 \%, 79 \%$, and $38 \%$, respectively, after 10 years of operation. The average soil temperature decreased by $7.3^{\circ} \mathrm{C}, 11^{\circ} \mathrm{C}$, and $4.3^{\circ} \mathrm{C}$, respectively, which resulted in obvious cold accumulation. The COP of the heat pump also decreased by $23 \%, 46 \%$, and $11 \%$, respectively. By the tenth year, the operation time of the system is increased by 186 hours, 437 hours, and 88 hours compared with the first year, respectively.

The dynamic simulation results in TRNSYS show that the proposed SA-GSHP system has great energy saving 

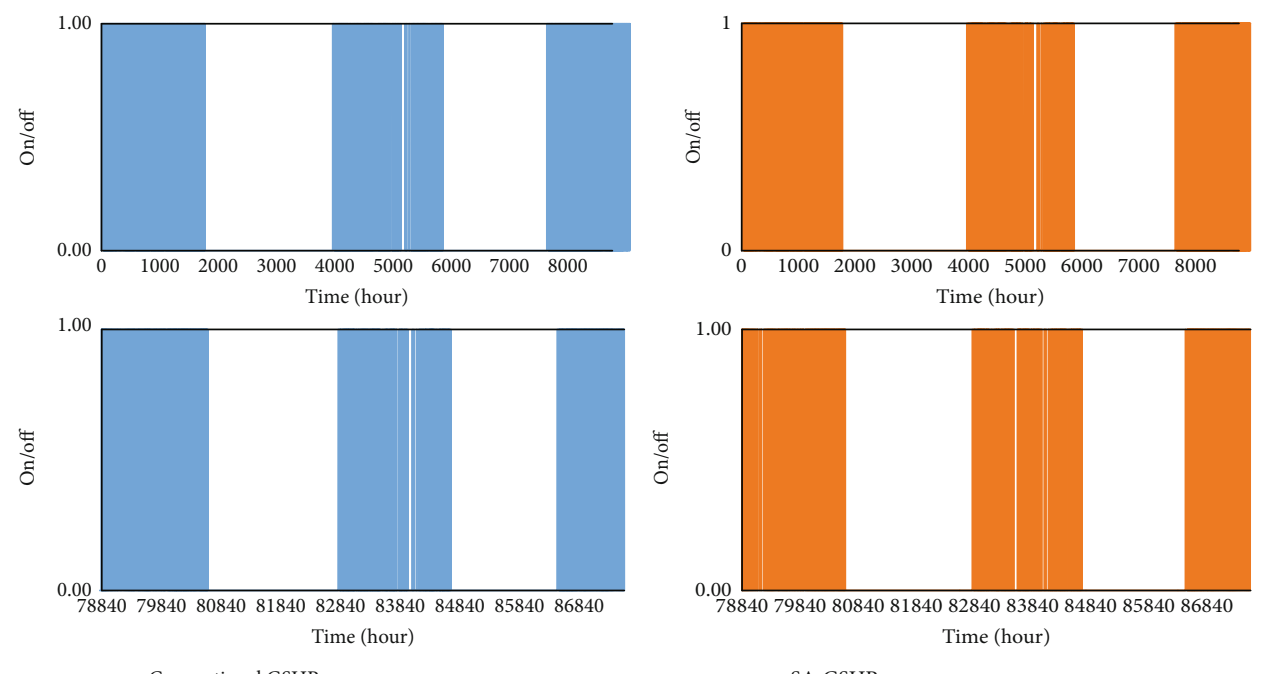

(a) Case 1 (Beijing)
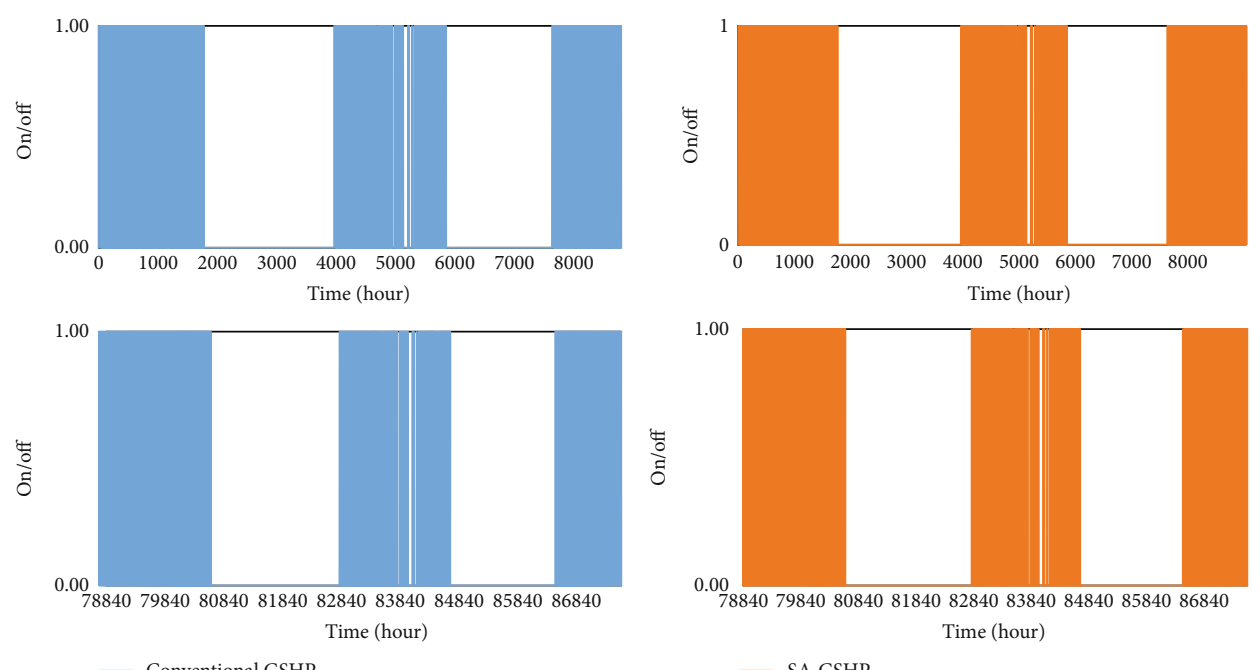

(b) Case 2 (Harbin)
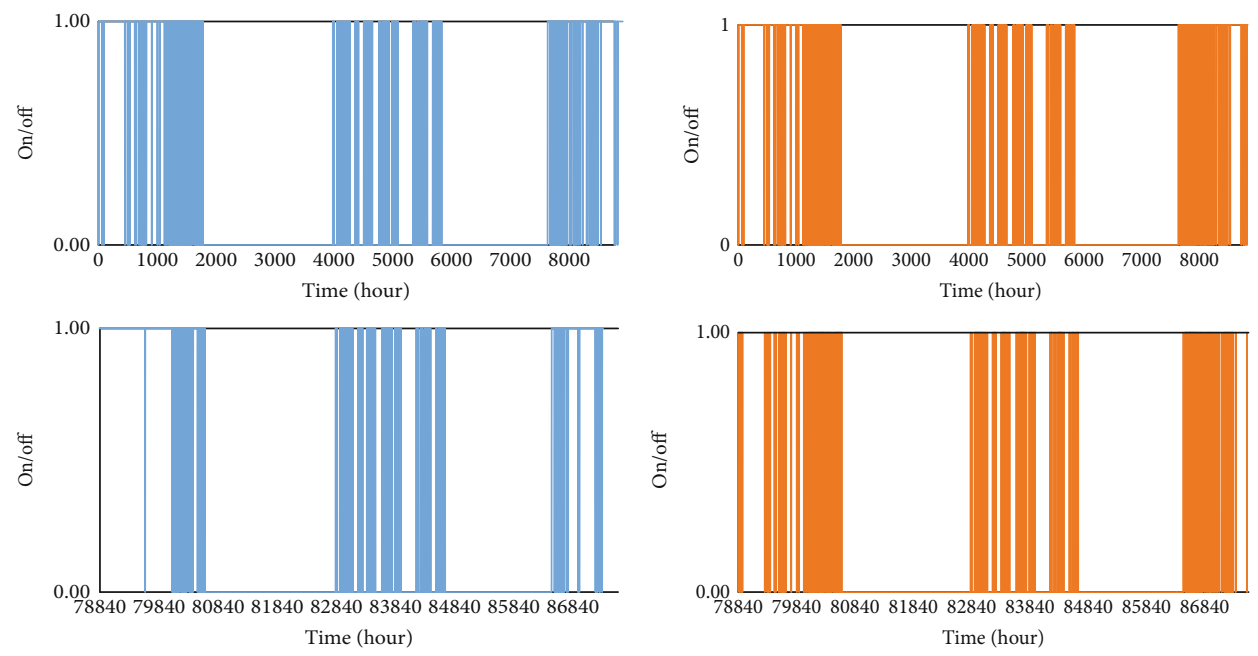

(c) Case 3 (Zhengzhou)

FIGURE 13: Ten-year trend in pump operating signal during heating for the GSHP and SA-GSHP systems. 
potential. The system operation time of SA-GSHP is shorter than that of GSHP which could save more energy. After the system is optimized, the solar collector area increases by $20 \%$ in the Beijing region, $25 \%$ in the Harbin region, and $15 \%$ in the Zhengzhou region could help to maintain the annual average soil temperature balance. The simulation results show that the system can stabilize space heating. By storing solar energy into the soil in the transitional season, the imbalance efficiency can be kept at $1 \%$ to decrease the phenomenon of cold accumulation in the soil and ensure the COP stability of the heat pump unit.

For the cold and severe cold region represented by Beijing and Harbin, it is suggested to add heat storage equipment to the GSHP system because soil temperature and COP decrease greatly. For a hot summer and cold winter region like Zhengzhou, soil temperature and COP have little change and there is no significant impact on equipment operation; it is not recommended to conduct heat storage.

\section{Nomenclature}

A: Heat transfer area $\left(\mathrm{m}^{2}\right)$

cp: Specific heat capacity $(\mathrm{kJ} /(\mathrm{kg} \cdot \mathrm{K}))$

$D: \quad$ Distance $(\mathrm{m})$

$f$ : $\quad$ Solar energy guarantee rate (\%)

$k_{c}$ : Time-varying coefficient

$h$ : Heat transfer coefficient $\left(\mathrm{W} / \mathrm{m}^{2} \cdot \mathrm{K}\right)$

L: $\quad$ Length (m)

$M_{c}$ : Total heat mass of the unit inside the borehole $\left(\mathrm{W} / \mathrm{m}^{2}\right)$

$\dot{\mathrm{m}}$ : Fluid flow rate $(\mathrm{kg} / \mathrm{s})$

$p$ : Pressure $(\mathrm{kPa})$

$P$ : $\quad$ Power $(\mathrm{kW})$

Pr: Prandtl number

Q: Heat transfer quantity $(\mathrm{kW})$

$q$ : Heat transfer rate per unit $\left(\mathrm{W} / \mathrm{m}^{2} \cdot \mathrm{K}\right)$

$r: \quad$ Radius $(\mathrm{m})$

$R: \quad$ Thermal resistance $\left(\mathrm{m}^{2} \cdot \mathrm{K} / \mathrm{W}\right)$

Re: Reynolds number

$S_{y}$ : Local average daily sunshine hours (h)

T: $\quad$ Temperature $(\mathrm{K})$

$U$ : Coefficient of heat transfer $\left(\mathrm{W} /\left(\mathrm{m}^{2} \cdot \mathrm{K}\right)\right)$

$v$ : Specific volume $\left(\mathrm{m}^{3} / \mathrm{kg}\right)$

$w$ : Specific work $(\mathrm{kW} / \mathrm{kg})$

$W$ : Work $(\mathrm{kW})$

$z: \quad$ Depth $(\mathrm{m})$

$\tau$ : Transmission coefficient.

\section{Subscripts}

B: $\quad$ Borehole

Con: Condensation

Cooling: Cooling season

Crit: Critical pressure

Exp: Experiment

Evp: Evaporation

Ex: $\quad$ Exothermic process

Heating: Heating season

In: $\quad$ Tube inlet

Num: Numerical
Min: Minimum

Max: Maximum

Natural: Natural convection

Out: Tube outlet

Pump: Pump.

\section{Greek Symbols}

$\alpha$ : Convective heat transfer coefficient $\left(\mathrm{W} /\left(\mathrm{m}^{2} \cdot \mathrm{K}\right)\right)$

$\varepsilon$ : Efficiency of the heat exchanger

$\eta$ : Efficiency

$\rho$ : Density $\left(\mathrm{kg} / \mathrm{m}^{3}\right)$

$\lambda$ : Thermal conductivity

$\theta$ : Temperature response.

Acronyms

COP: Coefficient of performance

GHE: Ground heat exchanger

GSHP: Ground source heat pump

SA-GSHP: Solar-assisted ground source heat pump.

\section{Data Availability}

The data used to support the findings of this study are available from the corresponding author upon request.

\section{Conflicts of Interest}

The authors declare no conflict of interest.

\section{Acknowledgments}

This work was financially supported by the National Natural Science Foundation of China (No. 51678024 and No. 51338006), High Level Innovation Team of Beijing Municipal Education Commission (No. IDHT20180512), and Fundamental Research Funds for Beijing University of Civil Engineering and Architecture (No. X18111 and No. X18301). We thank the Liwen Bianji, Edanz Editing China Office (http://www.liwenbianji.cn/ac), for editing the English text of a draft of this manuscript.

\section{References}

[1] I. Sarbu and C. Sebarchievici, "General review of groundsource heat pump systems for heating and cooling of buildings," Energy and Buildings, vol. 70, no. 1, pp. 441-454, 2014.

[2] C. Naldi, G. L. Morini, and E. Zanchini, "A method for the choice of the optimal balance-point temperature of air-towater heat pumps for heating," Sustainable Cities and Society, vol. 12, pp. 85-91, 2014.

[3] W. Choi, R. Ooka, and Y. Nam, "Impact of long-term operation of ground-source heat pump on subsurface thermal state in urban areas," Sustainable Cities and Society, vol. 38, pp. 429-439, 2018.

[4] Y. Bi, L. Chen, and F. Sun, "Comparative performance analysis for endoreversible simple air heat pump cycles considering ecological, exergetic efficiency and heating load objectives," International Journal of Exergy, vol. 6, no. 4, pp. 550-566, 2009. 
[5] A. Michopoulos, T. Zachariadis, and N. Kyriakis, "Operation characteristics and experience of a ground source heat pump system with a vertical ground heat exchanger," Energy, vol. 51, no. 51, pp. 349-357, 2013.

[6] W. Li, X. Lin, C. Cao, Z. Gong, and Y. Gao, "Organic Rankine cycle-assisted ground source heat pump combisystem for space heating in cold regions," Energy Conversion and Management, vol. 165, no. 1, pp. 195-205, 2018.

[7] S. Lazzari, A. Priarone, and E. Zanchini, "Long-term performance of BHE (borehole heat exchanger) fields with negligible groundwater movement," Energy, vol. 35, no. 12, pp. 49664974, 2010.

[8] Y. Geng, J. Sarkis, X. Wang, H. Zhao, and Y. Zhong, "Regional application of ground source heat pump in China: a case of Shenyang," Renewable \& Sustainable Energy Reviews, vol. 18, no. 2, pp. 95-102, 2013.

[9] M. Alavy, H. V. Nguyen, W. H. Leong, and S. B. Dworkin, "A methodology and computerized approach for optimizing hybrid ground source heat pump system design," Renewable Energy, vol. 57, no. 3, pp. 404-412, 2013.

[10] N. Zhu, P. Hu, L. Xu, Z. Jiang, and F. Lei, "Recent research and applications of ground source heat pump integrated with thermal energy storage systems: a review," Applied Thermal Engineering, vol. 71, no. 1, pp. 142-151, 2014.

[11] S. Paiho, H. Hoang, and M. Hukkalainen, "Energy and emission analyses of solar assisted local energy solutions with seasonal heat storage in a Finnish case district," Renewable Energy, vol. 107, pp. 147-155, 2017.

[12] S. Colclough and P. Griffiths, "Financial analysis of an installed small scale seasonal thermal energy store," Renewable Energy, vol. 86, pp. 422-428, 2016.

[13] W. Yang, J. Zhou, W. Xu, and G. Zhang, "Current status of ground-source heat pumps in China," Energy Policy, vol. 38, no. 1, pp. 323-332, 2010.

[14] S. Bae, Y. Nam, J. Choi, K. Lee, and J. Choi, "Analysis on thermal performance of ground heat exchanger according to design type based on thermal response test," Energies, vol. 12, no. 4, p. 651, 2019.

[15] K. Bakirci, O. Ozyurt, K. Comakli, and O. Comakli, "Energy analysis of a solar-ground source heat pump system with vertical closed-loop for heating applications," Energy, vol. 36, no. 5, pp. 3224-3232, 2011.

[16] F. M. Rad, A. S. Fung, and W. H. Leong, "Feasibility of combined solar thermal and ground source heat pump systems in cold climate, Canada," Energy and Buildings, vol. 61, no. 3, pp. 224-232, 2013.

[17] R. M. Lazzarin, "Dual source heat pump systems: operation and performance," Energy and Buildings, vol. 52, pp. 77-85, 2012.

[18] A. Macía, L. A. Bujedo, T. Magraner, and C. R. Chamorro, "Influence parameters on the performance of an experimental solar-assisted ground-coupled absorption heat pump in cooling operation," Energy and Buildings, vol. 66, pp. 282-288, 2013.

[19] C. Lyu, W. H. Leong, M. Zheng, G. Chen, S. Ye, and Y. Liu, "Verification and analysis of a dynamic simulation model of ground-coupled heat pump with solar seasonal heat storage system," Procedia Engineering, vol. 205, pp. 3154-3161, 2017.

[20] X. Wang, M. Zheng, W. Zhang, S. Zhang, and T. Yang, "Experimental study of a solar-assisted ground-coupled heat pump system with solar seasonal thermal storage in severe cold areas," Energy and Buildings, vol. 42, no. 11, pp. 2104-2110, 2010.
[21] M. Karagiorgas, K. Galatis, M. Tsagouri, T. Tsoutsos, and A. Botzios-Valaskakis, "Solar assisted heat pump on air collectors: a simulation tool," Solar Energy, vol. 84, no. 1, pp. 66-78, 2010.

[22] W. Liu, G. Chen, B. Yan, Z. Zhou, H. Du, and J. Zuo, "Hourly operation strategy of a CCHP system with GSHP and thermal energy storage (TES) under variable loads: a case study," Energy and Buildings, vol. 93, pp. 143-153, 2015.

[23] H. J. L. Witte, G. J. V. Gelder, and J. D. Spitler, "In situ measurement of ground thermal conductivity: the Dutch perspective," ASHRAE Transactions, vol. 108, no. 1, pp. 263-272, 2002.

[24] J. Luo, H. Zhao, J. Jia, W. Xiang, J. Rohn, and P. Blum, "Study on operation management of borehole heat exchangers for a large-scale hybrid ground source heat pump system in China," Energy, vol. 123, pp. 340-352, 2017.

[25] G. Emmi, A. Zarrella, M. De Carli, and A. Galgaro, "An analysis of solar assisted ground source heat pumps in cold climates," Energy Conversion and Management, vol. 106, pp. 660-675, 2015.

[26] W. Yang, M. Shi, G. Liu, and Z. Chen, "A two-region simulation model of vertical U-tube ground heat exchanger and its experimental verification," Applied Energy, vol. 86, no. 10, pp. 2005-2012, 2009.

[27] W. Yang, S. Zhang, and Y. Chen, "A dynamic simulation method of ground coupled heat pump system based on borehole heat exchange effectiveness," Energy and Buildings, vol. 77, no. 77, pp. 17-27, 2014.

[28] N. Diao, Heat Transfer Analyses of Ground Heat Exchanger and Their Engineering Applications[D], Tsinghua university, China, 2004.

[29] P. Hu, Z. Yu, N. Zhu, F. Lei, and X. Yuan, "Performance study of a ground heat exchanger based on the multipole theory heat transfer model," Energy and Buildings, vol. 65, no. 10, pp. 231241, 2013.

[30] M. Guo, N. Diao, Y. Man, and Z. Fang, "Research and development of the hybrid ground-coupled heat pump technology in China," Renewable Energy, vol. 87, pp. 1033-1044, 2016.

[31] T. Katsura, K. Nagano, S. Narita, S. Takeda, Y. Nakamura, and A. Okamoto, "Calculation algorithm of the temperatures for pipe arrangement of multiple ground heat exchangers," Applied Thermal Engineering, vol. 29, no. 5-6, pp. 906-919, 2009.

[32] A. F. Handbook, American Society of Heating, Refrigerating and Air-Conditioning Engineers, Inc, Atlanta, GA, USA, 2009.

[33] S. A. Klein, A Transient System Simulation Program, Solar Energy Laboratory, TRNSYS, University of Wisconsin, Madison, 2006.

[34] G. Florides and S. Kalogirou, "Ground heat exchangers-a review of systems, models and applications," Renewable Energy, vol. 32, no. 15, pp. 2461-2478, 2007.

[35] China Academy of Architectural Sciences, GB 50495-2009 Technical Specification for Solar Heating and Heating Engineering, China Construction Industry Press, Beijing, 2009. 